\title{
Nonadherence with antipsychotic medication in schizophrenia: challenges and management strategies
}

REVIEW

This article was published in the following Dove Press journal:

Patient Related Outcome Measures

23 June 2014

Number of times this article has been viewed

\section{Peter M Haddad ${ }^{1,2}$ \\ Cecilia Brain ${ }^{3,4}$ \\ Jan Scott $\mathrm{C}^{5,6}$}

'Neuroscience and Psychiatry Unit, University of Manchester, Manchester, ${ }^{2}$ Greater Manchester West Mental Health NHS Foundation Trust, Salford, UK; ' Institute of Neuroscience and Physiology, Department of Psychiatry and Neurochemistry, Sahlgrenska Academy, University of Gothenburg, ${ }^{4} \mathrm{Nå}$ Ut-teamet, Psychosis Clinic, Sahlgrenska University Hospital, Gothenburg, Sweden; ${ }^{5}$ Academic Psychiatry, Institute of Neuroscience, Newcastle University, ${ }^{6}$ Centre for Affective Disorders, Institute of Psychiatry, London, UK
Correspondence: Peter M Haddad Greater Manchester West Mental Health NHS Foundation Trust, Cromwell House, Eccles, Salford, M30 0GT, UK

Tel +44 I6I 7876007

Email peter.haddad@gmw.nhs.uk
Abstract: Nonadherence with medication occurs in all chronic medical disorders. It is a particular challenge in schizophrenia due to the illness's association with social isolation, stigma, and comorbid substance misuse, plus the effect of symptom domains on adherence, including positive and negative symptoms, lack of insight, depression, and cognitive impairment. Nonadherence lies on a spectrum, is often covert, and is underestimated by clinicians, but affects more than one third of patients with schizophrenia per annum. It increases the risk of relapse, rehospitalization, and self-harm, increases inpatient costs, and lowers quality of life. It results from multiple patient, clinician, illness, medication, and service factors, but a useful distinction is between intentional and unintentional nonadherence. There is no gold standard approach to the measurement of adherence as all methods have pros and cons. Interventions to improve adherence include psychoeducation and other psychosocial interventions, antipsychotic longacting injections, electronic reminders, service-based interventions, and financial incentives. These overlap, all have some evidence of effectiveness, and the intervention adopted should be tailored to the individual. Psychosocial interventions that utilize combined approaches seem more effective than unidimensional approaches. There is increasing interest in electronic reminders and monitoring systems to enhance adherence, eg, Short Message Service text messaging and real-time medication monitoring linked to smart pill containers or an electronic ingestible event marker. Financial incentives to enhance antipsychotic adherence raise ethical issues, and their place in practice remains unclear. Simple pragmatic strategies to improve medication adherence include shared decision-making, regular assessment of adherence, simplification of the medication regimen, ensuring that treatment is effective and that side effects are managed, and promoting a positive therapeutic alliance and good communication between the clinician and patient. These elements remain essential for all patients, not least for the small minority where vulnerability and risk issue dictate that compulsory treatment is necessary to ensure adherence.

Keywords: adherence, nonadherence, antipsychotics, schizophrenia, long-acting injections, relapse, risk factors

\section{Introduction}

The challenge of patients not following medical advice is not new. In the 4th century BC, Hippocrates observed that some patients did not take their prescribed treatments. ${ }^{1}$ In the 19th century, Robert Koch, the father of modern bacteriology, was critical of patients with tuberculosis who did not adhere to strategies to reduce infection. In 1955, soon after the introduction of antibiotics, it was observed that approximately one third of patients did not complete a 1-week course of oral penicillin for acute pharyngitis or otitis media. ${ }^{2}$ A recent national guideline concluded that between a third and one half of medicines that are prescribed for long-term conditions are not taken by 
patients as recommended by the prescriber. ${ }^{3}$ Poor adherence is not limited to medication-taking and encompasses other treatment recommendations or "healthy behaviors", such as exercise and diet. This is recognized by the World Health Organization, which defines therapeutic adherence as "the extent to which a person's behavior corresponds with agreed recommendations from a health care provider". ${ }^{4}$

Medication adherence can be defined as the extent to which a patient's medication-taking matches that agreed with the prescriber. A range of alternative terms have been used, including treatment compliance and fidelity, but adherence is currently favored partly due to its neutrality. In contrast, compliance implies an unequal power balance between the prescriber and patient. Medication adherence lies on a spectrum ranging from individuals who take no medication, despite agreeing with the prescribing clinician to do so, to those who take each dose precisely on time. In between these two extremes are patients who show varying degrees of adherence, taking some medication some of the time but not consistently as prescribed. This is termed partial adherence, and includes those who consistently miss doses on a regular basis and those who go through cycles of varying levels of adherence over time, eg, taking $100 \%$ of medication during a relapse but gradually reducing their intake when in remission. Problems with adherence can include taking excess medication, but this is less common, and this review is concerned with those who take less medication than prescribed. Adherence is usually dichotomized for research purposes and is often defined as missing at least $20 \%$ of the medication in question. This cutoff has validity in predicting subsequent hospitalization across several chronic conditions, ${ }^{5}$ although for individual patients the degree of nonadherence that affects health outcomes will vary and depend on multiple factors including the condition, its severity, the risk of recurrence, the relative effectiveness of the medication, and its dose and frequency of administration. In this paper, the term "nonadherence" is used to refer to total nonadherence and clinically relevant degrees of partial adherence.

Although nonadherence is a problem throughout medicine, there are several factors that make it especially challenging in schizophrenia. These include lack of illness awareness (a term encompassing insight, but also attitudes and beliefs about the nature of the illness), the direct impact of symptoms (including depression, cognitive impairment, and positive and negative symptoms), social isolation, comorbid substance misuse, stigma, and the increasing fragmentation of mental health services in many countries. Not surprisingly, these multiple disadvantages for people with schizophrenia mean the prevalence of nonadherence in psychosis is at least as high if not higher than in many chronic medical disorders. ${ }^{6}$ In this review, we concentrate on nonadherence with antipsychotic medication. We consider the prevalence of nonadherence, its costs, and the factors that contribute. Next we review the assessment of nonadherence in research studies and clinical practice. We review a range of interventions to improve adherence, including basic strategies that should accompany prescribing, specific psychosocial interventions, antipsychotic long-acting injections (LAIs), electronic reminders, service interventions, and financial incentives. In reality, there is overlap between some of these approaches. We conclude by highlighting some key areas for future research. Strategies to improve adherence assume that in clinical practice the benefits of antipsychotic medication are often undermined by nonadherence. In view of this, we start with a brief review of the evidence base for the use of antipsychotic medication in the management of schizophrenia.

\section{Antipsychotic medication and schizophrenia}

The course and outcome of schizophrenia show considerable variability between individuals. ${ }^{7}$ A small proportion of individuals experience a single psychotic episode, make a full recovery, and remain well without medication. However, for most of those affected, schizophrenia is a chronic condition, although this should not obscure the fact that the long-term prognosis is favorable or at least stable for a high proportion. In a 5-year follow-up of patients who experienced a first episode of psychosis, the cumulative first relapse rate was $82 \%$ and the second relapse rate was $78 \%{ }^{8}$ A systematic review of longitudinal studies in first-episode psychosis, with a mean follow-up of 35 months, reported a good outcome for $42 \%$ and a poor outcome for $27 \%$ of individuals. ${ }^{9}$

The efficacy of antipsychotic medication in the acute and maintenance treatment of schizophrenia is clear from large meta-analyses of placebo-controlled trials. A meta-analysis of 38 randomized controlled trials (RCTs) that compared second-generation antipsychotics with placebo in acute treatment of schizophrenia showed a moderate effect size of approximately 0.5 , with a number needed to treat of six for response. ${ }^{10}$ Another meta-analysis of 65 trials, in which patients stabilized on antipsychotic medication were randomized to continue medication or switch to placebo, showed that antipsychotics significantly reduced the rate of relapse at 1 year compared with placebo, with a number needed to treat to benefit of three (Figure 1). ${ }^{11}$ Those treated with 
antipsychotic drugs were also less likely to be admitted to hospital or to drop out for inefficacy or for any reason. ${ }^{11}$

Antipsychotics are not a panacea. Their benefit in acute treatment is largely in terms of the treatment of positive symptoms while other symptom domains, particularly negative symptoms, show less improvement. Some patients do not respond to antipsychotic medication including clozapine; the proportion of such patients is higher in tertiary services ${ }^{12}$ but treatment resistance occurs, albeit less frequently, in first-episode patients. ${ }^{13}$ Maintenance antipsychotic treatment does not eliminate the risk of relapse, but does reduce it. Antipsychotics can have a wide range of side effects. ${ }^{14}$ In the maintenance meta-analysis by Leucht et al, weight gain, sedation, and movement disorders were more common in those treated with antipsychotic medication than in those treated with placebo (Figure 1). ${ }^{11}$ Antipsychotic-induced weight gain, ${ }^{15}$ metabolic disturbance, ${ }^{16}$ and hyperprolactinemia ${ }^{17}$ are particularly important due to their potential impact on future physical health. Antipsychotics can also impair cognition. ${ }^{18}$ Many of these adverse effects are dose-related. ${ }^{14}$

There is growing interest in the possibility that carefully selected patients with schizophrenia may be able to be treated both acutely and long-term with psychological interventions as an alternative to medication. ${ }^{19}$ At present, the data are limited and such an approach cannot be advocated as routine practice. Most guidelines for the treatment of schizophrenia recommend that pharmacological relapse prevention strategies are considered for every patient diagnosed with schizophrenia, with treatment being continued for between 1 and 2 years after a first episode. ${ }^{20}$ In clinical practice, the duration of maintenance treatment needs to be determined on an individual patient basis by weighing up its advantages and disadvantages. Many patients require indefinite antipsychotic treatment, although this should be at the lowest effective dose and combined with psychosocial approaches and regular follow-up that includes monitoring for side effects, with intervention as appropriate.

\section{Prevalence of antipsychotic nonadherence}

Nonadherence with medication is a problem in all chronic medical conditions including, for example, the use of insulin in diabetes, ${ }^{21}$ antihypertensives in hypertension, ${ }^{22}$ brimonidine in glaucoma, ${ }^{23}$ antiretroviral therapy in those with human immunodeficiency virus, ${ }^{24}$ and statins in those with hyperlipidemia. ${ }^{25}$ A review of medication adherence in psychiatric and physical disorders, spanning papers published between 1975 and 1996, reported the mean amount of prescribed medication taken to be $58 \%$ for patients prescribed antipsychotics, $65 \%$ for those prescribed antidepressants, and $76 \%$ for those prescribed medication for physical disorders. ${ }^{6}$

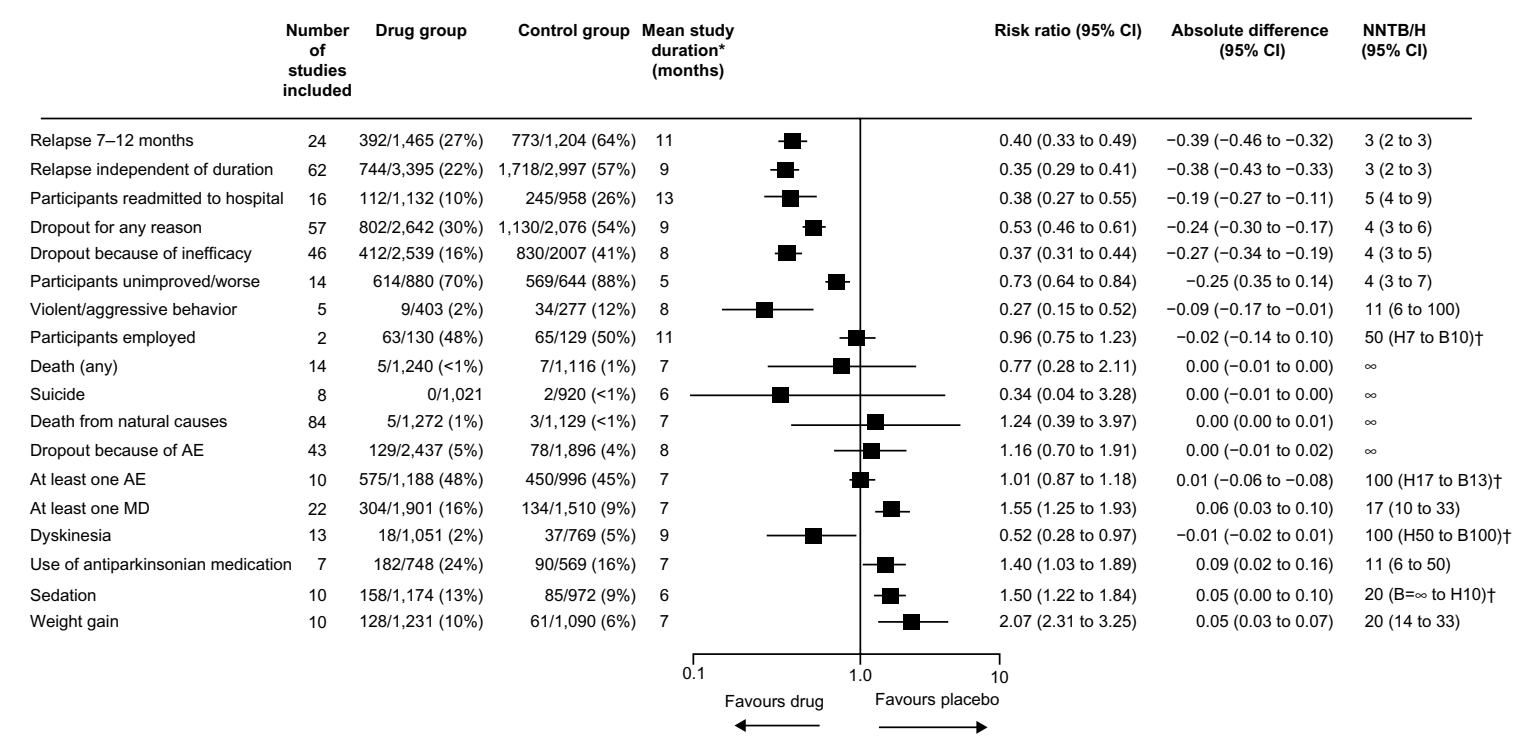

Figure I Efficacy of maintenance antipsychotic medication versus placebo in schizophrenia $(65$ trials, $n=6,493)$.

Notes: Data are n/N (\%) unless otherwise stated. The random effects model by DerSimonian and Laird ${ }^{144}$ was used throughout, with weights calculated by the MantelHaenszel method. *Weighted by sample size of individual trials. 'Because of space limitations, we did not use the display suggested by Altman. ${ }^{145}$ Reprinted from The Lancet, 379, Leucht S, Tardy M, Komossa K, et al, Antipsychotic drugs versus placebo for relapse prevention in schizophrenia: a systematic review and meta-analysis, 2063-207I, Copyright (C) 2012, with permission from Elsevier."

Abbreviations: AE, adverse event; MD, movement disorder; $n$, number of participants with an event; $N$, number of studies; $C l$, confidence interval; NNTB/NNTH, number needed to treat to benefit/harm; $\mathrm{H}$, harm; $\mathrm{B}$, benefit. 
The authors concluded that nonadherence may be a greater issue in psychiatry than in general medicine, but that the difference could reflect differences in the methodology used to assess adherence. Studies using electronic monitoring show that the extent of antipsychotic nonadherence is underestimated by psychiatrists. ${ }^{26}$

The rate of nonadherence with antipsychotics in schizophrenia varies between studies, reflecting differences in the populations studied and the methodology used in terms of the definition and measurement of adherence and the period of time over which it is assessed (see Assessment of nonadherence section). However, there is a clear consensus that nonadherence is a major problem. A systematic review of 39 studies reported a mean rate of medication nonadherence in schizophrenia of $41 \% .{ }^{27}$ When the analysis was restricted to the five methodologically most rigorous studies, which included defining adherence as taking medication at least $75 \%$ of the time, the nonadherence rate increased to $50 \%$.

Valenstein et al assessed approximately 34,000 Veterans Affairs patients with schizophrenia. ${ }^{28}$ Medication possession ratios (MPRs, ie, percentage of days with an antipsychotic prescription) were calculated for 4 consecutive years, with good adherence defined as an MPR $\geq 0.8$ during a year. Patients were divided into those who had consistently poor adherence (MPR $<0.8$ in all years) and consistency good adherence (MPR $\geq 0.8$ in all years). The cross-sectional prevalence of poor adherence was stable over time, with about $36 \%$ being poorly adherent each year. Adherence was not a stable trait, and when assessed over 4 years, $18 \%$ of subjects had consistently poor adherence, $39 \%$ had consistently good adherence, and $43 \%$ were inconsistently adherent. Thus, in total, $61 \%$ of patients had at least 1 year during which they showed poor adherence. Those with consistently poor adherence were more likely to be younger, nonwhite, have comorbid substance misuse, and to have been admitted to a psychiatric hospital. This study, like many, would underestimate nonadherence because it assumes that collecting medication from a pharmacy equates to taking it.

\section{Costs of nonadherence}

Nonadherence with antipsychotic medication can lead to relapse for patients in remission and persistent symptoms for those with existing symptoms, and both scenarios can cause multiple patient and service costs (Figure 2). The costs of nonadherence were demonstrated in a 3-year, prospective, observational study of schizophrenia in the USA in which a composite measure of patient-reported adherence and MPR was used to determine adherence. ${ }^{29}$ Outcome data were gathered at regular points throughout the study by reviewing medical records and conducting structured interviews with the participants. Nonadherence was associated with a significantly higher rate of psychiatric hospitalization, use of emergency psychiatric services, arrest, violence, victimization, and substance use (Figure 3) plus poorer mental functioning,

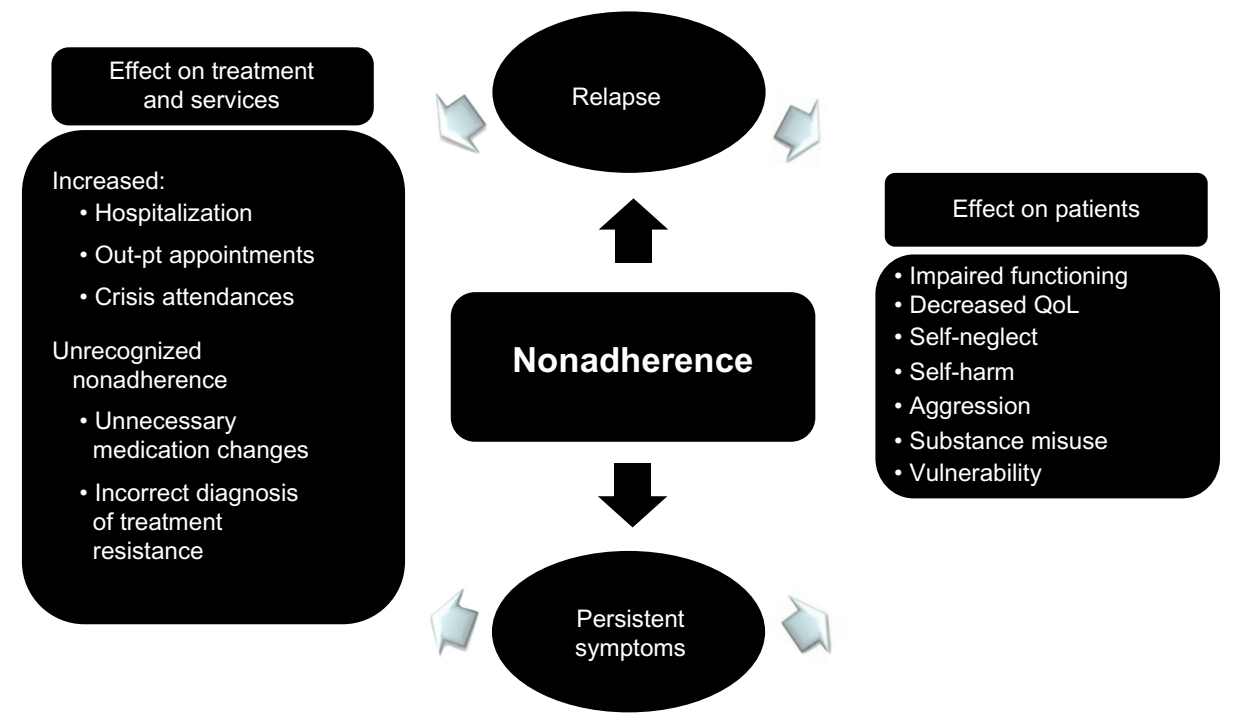

Figure 2 Consequences of nonadherence to antipsychotic medication.

Note: This material was originally published in Antipsychotic long-acting injections (edited by P Haddad, T Lambert and J Lauriello) and has been reproduced by permission of Oxford University Press. http://ukcatalogue.oup.com/product/9780199586042.do. For permission to reuse this material, please visit http://www.oup.co.uk/academic/rights/ permissions. ${ }^{146}$

Abbreviation: QoL, Quality of life. 


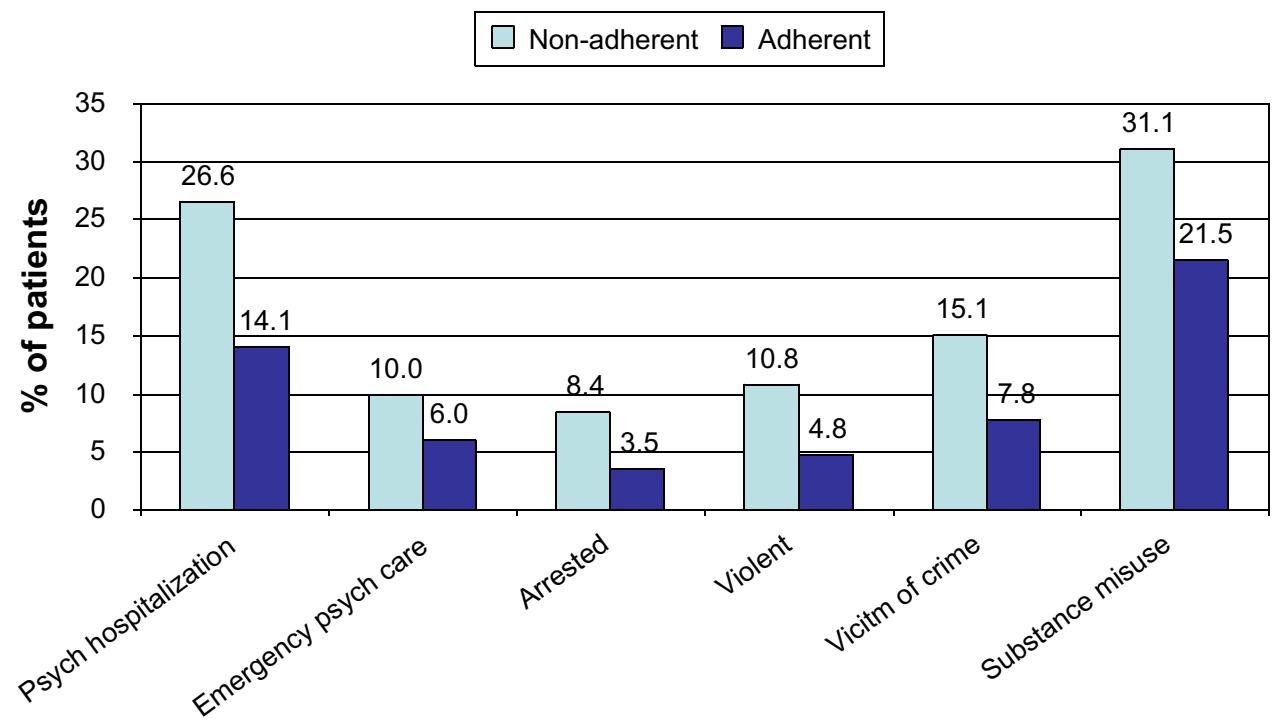

Figure 3 Association between antipsychotic nonadherence and outcome in a 3-year prospective observational US study.

Notes: Adherence based on patient-reported adherence and medication possession ratio (\% days with prescription for any antipsychotic). Data adapted from Ascher-Svanum H, Faries DE, Zhu B, Ernst FR, Swartz MS, Swanson JW. Medication adherence and long-term functional outcomes in the treatment of schizophrenia in usual care. J Clin Psychiatry. 2006;67(3):453-460. ${ }^{29}$ Copyright @ 2006, Physician's Postgraduate Press, Inc.

Abbreviation: Psych, psychiatric.

poorer life satisfaction, and more alcohol-related problems. Nonadherence in the first year predicted significantly poorer outcomes in the following 2 years. A 3-year, prospective, observational, European study of outpatients with schizophrenia found that nonadherence was significantly associated with an increased risk of relapse, hospitalization, and suicide attempts. ${ }^{30}$ An association between antipsychotic nonadherence and an increased rate of self-harm ${ }^{31}$ and suicide ${ }^{32}$ has been reported in other studies. A recent analysis from the CUTLASS (Cost Utility of the Latest Antipsychotic Drugs in Schizophrenia Study) clinical trial in the UK showed that improved antipsychotic adherence led to improved quality of life. ${ }^{33}$

Relatively short periods of nonadherence have been linked to poorer outcomes. Two US studies, both using pharmacy refills to measure adherence, found that missing medication for 10 days was associated with an increased risk of psychiatric hospitalization..$^{34,35}$ In one study, the risk of hospitalization was correlated with the degree of nonadherence, with a gap of 1-10 days in antipsychotic medication being associated with an odds ratio for admission of 1.98, a gap of 11-30 days with an odds ratio of 2.81, and a gap of more than 30 days with an odds ratio of $3.96 .{ }^{35}$ It is important to highlight that the degree of nonadherence leading to poorer clinical outcomes will vary greatly between individuals and be influenced by multiple factors. Patients with a low risk of relapse may remain well despite marked degrees of nonadherence. This may explain why some intervention studies of nonadherence report improved medication adherence but without improvement in clinical outcomes.

Relapse after a first episode of psychosis can be particularly damaging, as those affected are likely to be relatively young and at a critical period in their life. The only factor predictive of relapse in a 3-year follow-up of first-episode patients was medication nonadherence. ${ }^{36}$ In a separate 5-year, follow-up study, discontinuation of medication after a first psychotic episode increased the risk of relapse by five-fold. ${ }^{8}$ Successive relapses in schizophrenia are associated with a decrease in treatment response ${ }^{37}$ and possibly a worsening of the disease process ${ }^{38}$ and brain shrinkage. ${ }^{39}$ Irrespective of organic mechanisms, successive relapse is likely to lead to accrual of disability, because each relapse can damage an individual's confidence, social networks, and employment opportunities.

The impact of antipsychotic nonadherence on economic costs in people with schizophrenia is complex and varies across services. ${ }^{40}$ QUATRO (Quality of Life following Adherence Therapy for People Disabled by Schizophrenia and their Carers), a multicenter European RCT, found that community-based day service costs and societal costs were lower among nonadherent patients with schizophrenia and that nonadherence was not significantly associated with total health and social care costs. ${ }^{40}$ In contrast, two systematic reviews, one of seven studies conducted in the USA ${ }^{41}$ 
and one of eight studies conducted worldwide, ${ }^{42}$ found that nonadherence was associated with higher hospitalization rates and direct health care costs. The national rehospitalization cost in the USA attributable to antipsychotic nonadherence was estimated at approximately $\$ 1,500$ million per year in $2005 .^{41}$

When nonadherence is covert, it may lead to the incorrect assumption that an antipsychotic drug is ineffective, which may result in an inappropriate change of treatment, including an increase in the dose of the antipsychotic drug, switching to another antipsychotic agent, or the addition of other medications. A trial of an antipsychotic LAI can be a helpful way to determine whether symptoms in a patient previously prescribed an oral antipsychotic medication are the result of covert nonadherence or represent treatment resistance.

\section{Factors associated}

\section{with nonadherence}

A useful way to conceptualize nonadherence is to consider intentional and unintentional nonadherence. ${ }^{3}$ Intentional nonadherence occurs when a patient makes a deliberate decision not to take medication as prescribed. This is usually because the disadvantages of medication are perceived as outweighing the benefits, ie, it can be understood by a health beliefs model. Unintentional nonadherence occurs when practical problems interfere with adherence. Examples

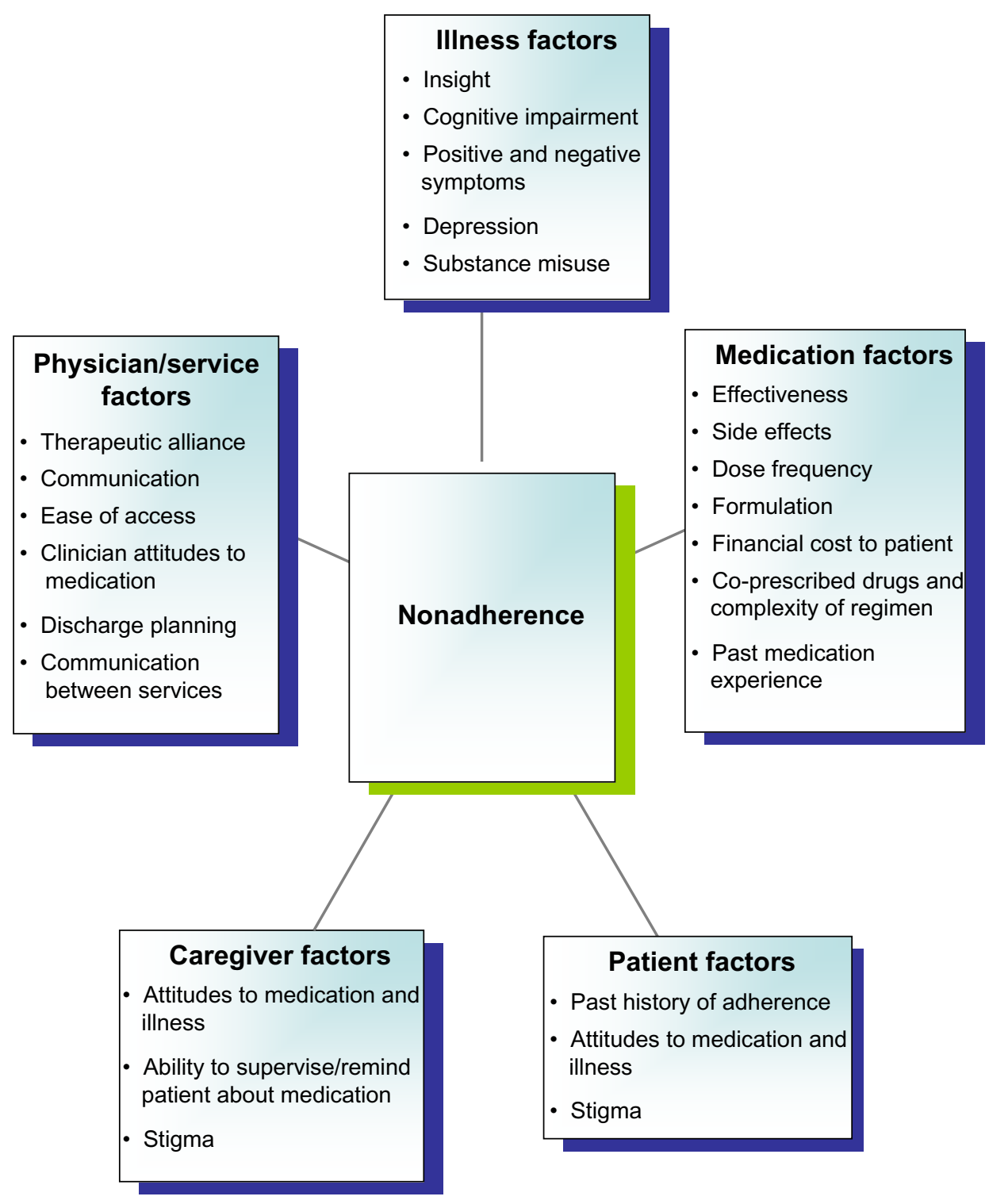

Figure 4 Factors associated with nonadherence. 
include the patient forgetting to take medication, not understanding the instructions that they were given about medication-taking, or having difficulty collecting repeat prescriptions from a pharmacy due to either travel issues or the medication cost. Both types of nonadherence may occur in the same patient.

Figure 4 summarizes some of the key factors associated with nonadherence based on previous studies. ${ }^{43,44}$ Poor adherence cannot simply be regarded as "difficult" behavior on behalf of the patient; rather, it can result from a range of factors that encompass the illness, medication, and organization of services, plus attributes of the clinician, patient, and caregivers. As a result, improving adherence often requires a range of interventions.

In terms of illness factors, multiple studies have linked poor insight, or unawareness of illness and the need for treatment, to nonadherence. ${ }^{45,46}$ Poor insight was regarded as the most important factor contributing to nonadherence in serious mental illness in a survey of experts. ${ }^{47}$ Insight is not a stable trait and often improves during the course of treatment. ${ }^{48}$ Cognitive impairment is associated with nonadherence ${ }^{49}$ and predicts relapse after a first episode of psychosis. ${ }^{50}$ Psychotic symptoms may impact directly on adherence, for example, the content of a delusion may be that medication is a poison, while auditory hallucinations may instruct a person not to take medication. Negative and depressive symptoms can decrease an individual's motivation to collect and take medication. ${ }^{51}$ Alcohol and illicit drug misuse, common comorbidities in schizophrenia, ${ }^{52}$ both predict antipsychotic nonadherence. ${ }^{30}$

The effectiveness of antipsychotic medication is a key determinant of adherence. In a pooled analysis of data from RCTs, reduction in the Positive and Negative Syndrome Scale positive factor was the strongest predictor of treatment adherence, irrespective of the antipsychotic. ${ }^{53}$ Conversely, a poor response to medication is one of the most frequent reasons why patients leave clinical trials. This highlights that clinicians should ensure that patients are aware of the time course for symptom improvement after starting antipsychotic medication and discuss switching to another antipsychotic, including clozapine when appropriate, if patients do not respond to an adequate trial of a medication. The association between side effects and nonadherence is complex. ${ }^{27,54}$ RCTs often report "dropouts" due to side effects or adverse effects, but individual perceptions or beliefs about the illness or the treatments are not recorded. In the real world, patients often suggest that it is not side effects per se that are the problem, but lack of knowledge about the danger or otherwise of each side effect and lack of skills or management strategies to cope with side effects, ie, subjective or practical issues rather than the objective severity of a side effect may be most relevant in dictating adherence behaviors. ${ }^{55-57} \mathrm{~A}$ patient who perceives a drug as beneficial and important to their recovery may continue to take it despite it causing significant side effects. In contrast, a patient who sees little benefit from medication and is unconvinced by the explanation of their diagnosis or need for pharmacotherapy may stop treatment at the first sign of a side effect that causes relatively minor inconvenience to others. In this case, one could argue that it is the patient's attitude to the medication rather than the side effect that is the chief cause of nonadherence.

Another aspect of medication that needs to be considered is the financial cost to the patient. A study in the USA found that higher patient cost-sharing (eg, copayments or coinsurance) was associated with a lower likelihood of adherence with antipsychotic medication and a shorter time to discontinuation of medication. ${ }^{58}$ In another study, schizophrenia patients who perceived copayment burden were less than half as likely to have complete adherence. ${ }^{59}$ This result needs to be considered in light of the study's methodological weaknesses that included a cross-sectional design and use of self-reported patient data. Complex medication regimens, including, for example, higher dosing frequency and complicated instructions for drug-taking, can reduce the likelihood of adherence in various disease areas. ${ }^{60,61}$ Simplifying the treatment regimen can improve adherence, ${ }^{62}$ although this strategy may be ineffective if other barriers to adherence, in particular negative attitudes to medication, persist. ${ }^{63,64}$ The role of antipsychotic formulation, and in particular LAIs, as a determinant of adherence is discussed in a later section on antipsychotic LAIs.

Patients who hold a negative drug attitude, for example as assessed by the Drug Attitude Inventory, ${ }^{64}$ are more likely to show poor adherence. ${ }^{43,65}$ In contrast, patient demographic variables, including age, sex, social class, and ethnicity, do not show a consistent relationship with antipsychotic adherence. ${ }^{66}$ Adherence can vary over time, but past nonadherence is a strong predictor of future nonadherence..$^{30,67}$

Many patients with schizophrenia are socially isolated and do not have relatives, friends, or caregivers to remind them to take medication. Stigma and negative perceptions about mental illness and psychiatric medication are widespread, and can contribute to poor adherence. ${ }^{68}$ Over half of a randomly selected general population sample in Switzerland 
in 1999 believed that antipsychotics carried a high risk of dependency. ${ }^{69}$ In a Swedish study, the drug attitude of the next-of-kin was associated with antipsychotic adherence in people with schizophrenia. ${ }^{43}$

The quality of the therapeutic relationship and clinicianpatient communication influence adherence. A European multicenter study investigated the relationship between antipsychotic adherence and the therapeutic relationship between patients with schizophrenia and clinicians, including psychiatric nurses, psychiatrists, social workers, and psychologists. ${ }^{70}$ Clinician and patient ratings of the therapeutic relationship were independently associated with better adherence with antipsychotic medication but only weakly intercorrelated. This implies that each perspective, although important, reflects a separate aspect of the relationship. The results do not necessarily indicate causality; it may be that more adherent patients form better therapeutic relationships with staff or that a good therapeutic relationship leads to better adherence, or there may be causality in both directions. However, other research suggests that communication and the therapeutic relationship influence adherence. A study conducted in the UK found that the attitude of inpatients with schizophrenia to their treatment, and their self-reported medication adherence, were both predicted by their perceived relationship with staff, especially the relationship with the physician-prescriber. ${ }^{71}$ A negative attitude to medication was also predicted by poor insight and experience of coercion during admission. The authors concluded that enhancing therapeutic relationships may lead to better outcomes.

In another study, the quality of communication between psychiatrists and patients with schizophrenia, in particular the psychiatrist responding to the patient's request for clarification, was associated with improved medication adherence. ${ }^{72}$ This is consistent with a meta-analysis in which physician communication (psychiatrists were not included) was positively correlated with patient adherence. ${ }^{73}$ The risk of nonadherence was $19 \%$ higher for patients whose physician communicated poorly, than for patients whose physician communicated well. ${ }^{73}$ This analysis also showed that training doctors in communication skills led to improvements in patient adherence.

Practical aspects of service design can impact on adherence. Ease of access to a psychiatrist, ${ }^{74}$ a consistent relationship with a single clinician, and ensuring sufficient time in appointments to discuss prescribing decisions and their place in the overall treatment plan are helpful in promoting adherence. Regular reminders from staff about the importance of medication-taking and assertive follow-up of patients who miss appointments can also assist adherence.
Table I Methods of assessing medication adherence

\begin{tabular}{ll}
\hline $\begin{array}{l}\text { Objective adherence } \\
\text { measurement }\end{array}$ & $\begin{array}{l}\text { Subjective adherence } \\
\text { measurement }\end{array}$ \\
\hline $\begin{array}{l}\text { Medication container with } \\
\text { electronic monitoring, eg, MEMS }\end{array}$ & $\begin{array}{l}\text { Clinician's view on adherence (often } \\
\text { based on therapeutic response and } \\
\text { side effects) }\end{array}$ \\
$\begin{array}{l}\text { Pill count } \\
\text { Biological markers }\end{array}$ & $\begin{array}{l}\text { Patient or key other report* } \\
\text { Observed intake }\end{array}$ \\
$\begin{array}{l}\text { Medication possession ratio } \\
\text { Medication plasma level }\end{array}$ & Questionnaires, eg, DAl, MARS \\
$\begin{array}{l}\text { Electronic ingestible event } \\
\text { marker }\end{array}$ & \\
\hline $\begin{array}{l}\text { Note: *Patient, case manager, other health care professional, next-of-kin, or carer } \\
\text { are asked to estimate the adherence of the patient. } \\
\text { Abbreviations: MEMS, Medication Event Monitoring System; DAl, Drug Attitude } \\
\text { Inventory; MARS, Medication Adherence Rating Scale. }\end{array}$
\end{tabular}

\section{Assessment of nonadherence}

In this section, we review the main methods used to assess nonadherence in research studies, and conclude with some recommendations for assessment of adherence in clinical practice. Multiple methods have been used in research studies to quantify adherence, and the choice of method greatly impacts the findings. ${ }^{75}$ For example, in one study, the prevalence of nonadherence was $0 \%$ when assessed by the Clinician Rating Scale and 48\% when assessed electronically using the Medication Event Monitoring System (MEMS). ${ }^{26}$ Methods to measure adherence can be divided into subjective and objective strategies (Table 1). Each method has its advantages and disadvantages, and no method is ideal.

Subjective ratings of adherence have poor validity and tend to underestimate nonadherence. ${ }^{26,75}$ The most common method is to ask the patient to rate their adherence level; this approach has high specificity (ie, if the patient says they are not taking the medication, this is likely to be true), but low sensitivity. Another approach is for clinicians to make a judgment about adherence, and this may take account of the observed clinical effectiveness and side effects of the medication. This approach is highly unreliable, as many factors can impact on the clinical state. In particular, one individual may remain well and not experience a relapse for a long period after stopping an antipsychotic medication, whereas another may relapse very quickly. Other subjective strategies to measure adherence include diaries in which the patient records their medication-taking, and rating scales and questionnaires where the patient, caregiver, case manager, or psychiatrist are asked to estimate adherence.

Objective measures to assess nonadherence are more accurate, and include electronic medication monitoring systems such as MEMS. The MEMS medication bottle cap is equipped with a microprocessor that records each time 
the bottle is opened. This, and other "smart" pill containers, are generally considered the reference standard in adherence studies. ${ }^{76} \mathrm{~A}$ drawback is that the potential discarding of pills cannot be detected because it is impossible to know if the patient actually ingests the medication after opening the cap of the MEMS bottle. Electronic medication containers have been adapted into a more sophisticated system that allows real-time wireless monitoring of medicationtaking (see the later section on Electronic reminders for further discussion). Despite high reliability and predictive validity, ${ }^{77}$ electronic monitoring is rarely used in adherence studies or in clinical practice because it is time-consuming and costly.

Pill count is a more clinically manageable objective measure which has been shown to be highly correlated with MEMS. ${ }^{75}$ Drawbacks of pill count include the requirement for regular follow-up and the potential risk of the patient discarding pills, without ingesting, which cannot be monitored. ${ }^{78}$ Nevertheless, in clinical practice, pill count can be a valuable tool to assess adherence. ${ }^{75}$

An example of the use of a biological marker to objectively assess adherence is the use of glycated hemoglobin to monitor diabetes. However, biological markers of antipsychotics are not clinically available. Observing intake of oral medication is difficult outside inpatient settings, and even then patients can secrete medication, sometimes going to great lengths to hide their nonadherence. Examples include patients secretly spitting out tablets or putting cotton wool in their mouths to absorb liquid formulations of medication. Monitoring the MPR is difficult other than in research studies, although an attempt has been made to use it in clinical practice. $^{79}$

Use of plasma drug levels to monitor adherence is not straightforward. Relatively little data are available regarding the therapeutic plasma levels of most second-generation antipsychotics. Interindividual variability in plasma levels is considerable, and medication metabolism, smoking, and other medications may affect the levels. Sometimes a blood drug level is requested, but without the time of the last antipsychotic dose being recorded; without this information, interpretation of the plasma level is impossible. A further issue is that a plasma level only provides information about medication adherence in the days immediately prior to the assay. Patients can increase their drug intake by taking loading doses prior to plasma sampling with the intention of deliberately concealing nonadherence. Some studies have defined adherence in terms of consistency between repeated plasma levels. This assesses stability over time, but does not take into account whether or not the levels are therapeutic. Furthermore, it only provides information about medication taking immediately prior to blood sampling; plasma levels and medication adherence in the intervening periods remain unknown. Several studies have compared adherence as determined by plasma levels with another objective adherence measure and have found plasma monitoring to be unreliable to determine adherence. In one study, a nonadherence rate of $23 \%$ was found with plasma levels and $40 \%$ with pill count. ${ }^{44}$ Another study found a nonadherence rate of $51 \%$ with plasma levels and $37 \%$ with MEMS. ${ }^{80} \mathrm{~A}$ recent Swedish study reported poor concordance between adherence as assessed by MEMS and plasma levels (concordance 56\%, kappa 0.05$).{ }^{75}$ In the $44 \%$ of patients where the two methods disagreed, patients were more frequently classified as nonadherent by plasma levels and adherent by MEMS than vice versa. ${ }^{75}$ In the clinic, interpretation of an occasional plasma level is problematic for all the reasons already discussed. If misinterpreted, the plasma level can lead to inappropriate changes in antipsychotic drug dose or the patient incorrectly being considered treatment-resistant.

The most recent development in objective assessment of adherence is the development of an electronic "ingestible event marker" that forms part of a digital health feedback system. ${ }^{81,82}$ The system uses a nontoxic digital ingestion sensor, approximately $1 \mathrm{~mm}$ square, that is embedded in a tablet. Following activation by gastric fluids, the ingested sensor wirelessly communicates with a small external monitor, currently a skin patch device worn by the patient, to record the date and time of ingestion. After several minutes of transmission, the sensor becomes inactive, and following normal transit through the gastrointestinal system, it is eliminated in the feces. The external monitor also collects physiological measures, including activity, sleep, and heart rate. At intervals, the monitor transfers data to a mobile phone which in turn relays it to a secure server. Summary reports can be produced and viewed on web-based systems by the patient and others that they consent to the information being shared with.

The feasibility and safety of the system was recently reported in a small study $(n=28)$ of patients with schizophrenia or bipolar disorder over a 4 -week period. ${ }^{81}$ Because this was a feasibility study, the digital ingestion sensor was embedded in a placebo tablet and the main outcome was the accuracy of the system to detect ingestion of the tablet compared with direct observation of ingestion. The researchers concluded that the system was accurate, safe, and acceptable to a large proportion of those who took 
part. Limitations of the study were the small sample size, short follow-up period, and the fact that those who took part were relatively well (score of 3 or less on the Clinical Global Impressions Scale) and likely to have been relatively adherent prior to entry. Small feasibility studies have also assessed this technology in patients with hypertension, heart failure, and tuberculosis. ${ }^{82}$ The advantage of the system over MEMS is that it records ingestion of a tablet and not simply the opening of a medication bottle. The system has the potential to be linked to an intervention to improve adherence by providing patients and health care professionals with feedback regarding adherence and other monitored parameters. Larger studies are required, and the place of this technology as an aid to assessing and potentially improving adherence in schizophrenia and other chronic conditions has yet to be established.

In clinical practice, a first step to improving the assessment of adherence is to ensure that sufficient time is made available in the consultation to explore this area. Nonadherence often remains covert because clinicians do not inquire about it; rather taking a "medication history" is confined to documenting the prescribed drugs and their doses with the assumption that the patient adheres to the prescription. When adherence is assessed, it is often done very briefly. To elicit the extent of nonadherence requires time, with questions being asked in a nonjudgmental manner. For example, the authors suggest that the following two simple questions might be used:

"Most people find it hard to stick perfectly to the treatment plan all the time; do you ever have any problems taking all the medications as prescribed?" Or "Do you ever try and cope with the illness on your own without taking the medications?"

The latter question is useful because it often exposes "intentional nonadherence", but also acknowledges that the patient is not trying to undermine their recovery, but often genuinely wants to get better through their own efforts. If these screening questions reveal nonadherence, it is helpful to try and quantify this, for example, with a question such as: "How many day's medication do you think you may have missed in the last ten days?"

Some patients are reluctant to discuss nonadherence with their psychiatrist, ${ }^{83}$ but may be more willing to discuss their medication-taking with other members of the clinical team, for example, a community psychiatric nurse, case manager, key worker, or support worker. This highlights the importance of the full multidisciplinary team being aware of the importance of adherence. A pill count can be performed at the outpatient clinic, if a patient brings their medication, or at a home visit. It can inform a wider discussion with the patient and can be combined with psychoeducation focused on medication, its effectiveness, side effects, and adherence. A key challenge is to create destigmatized methods and environments where patients are assisted to openly discuss their medication-taking.

\section{Introduction to interventions to improve adherence}

In the following section, we consider interventions to improve adherence with antipsychotic medication. We start by considering basic strategies that should routinely accompany prescribing decisions. Next, we consider specific interventions under five headings, ie, psychosocial interventions (psychoeducation, behavioral interventions, motivational interviewing, and cognitive approaches), antipsychotic LAIs, electronic reminders, service interventions, and financial incentives. In reality, some of these strategies overlap. Within the relevant sections we have not included every study, but provide a selective review of those that are most relevant for clinicians working in general psychiatry settings.

\section{Basic strategies to accompany prescribing}

Involving patients in decisions about their medication is crucial to improving adherence. ${ }^{3}$ The clinician needs to listen to the patient, understand their perspective, including their beliefs and concerns about their illness and medication, and ensure that their preferences regarding treatment are based on fact rather than misperceptions. Involving patients in the choice of their medication increases the likelihood of adherence. ${ }^{84,85}$ The amount of information required will vary between patients. Where possible, a choice of medication should be offered. If the patient has a key carer or relative and is agreeable, then it can help to involve the carer in these discussions. Given that antipsychotics, other than clozapine, show little difference in efficacy but can vary markedly in side effect profile, ${ }^{14}$ choice will often be governed by side effects and sometimes by formulation. Decisions on psychiatric prescribing are often made quickly without paying sufficient attention to these issues. In a study based on videoing psychiatric outpatient consultations, a medication decision took approximately 2 minutes and the mean degree of patient involvement was low. ${ }^{86}$ The benefit of involving patients with severe mental illness in choice of medication is supported by a study on advance directives, 
ie, legal documents that allow patients to communicate their medication preferences for future treatment should their capacity to make such decisions become impaired. ${ }^{85}$ Following the advance directive, patients showed improved adherence even when the crisis these documents were designed for had passed.

It is important that patients are warned of side effects before starting medication. Tolerance develops to some side effects. Titrating the dose upwards gradually and/or explaining to the patient that side effects should settle can reduce the likelihood of side effects impairing adherence. Managing side effects that emerge during treatment depends on their detection at review appointments. If patients have a good therapeutic alliance with the clinical team, particularly the prescriber, then they are more likely to volunteer side effects. The use of a simple checklist can also aid the detection of side effects. Examples of two simple and easy to complete antipsychotic side effect checklists are the Systematic Monitoring of Adverse Events Related to Treatments (SMARTS) ${ }^{87}$ and the Glasgow Antipsychotics SideEffect Scale (GASS). ${ }^{88}$ Both can be completed by patients in the waiting room prior to a consultation and form the focus of a clinical discussion about side effects. The impact of side effects can sometimes be reduced by altering the timing of medication-taking. For example, if clozapine is causing sedation, the greater part of the dose can be taken at nighttime rather than splitting the dose equally between morning and night-time. Other strategies to manage side effects include dose reduction, although one needs to consider the risk of this precipitating a relapse, and recommending a specific treatment for a side effect. Examples include sipping water if the medication has caused a dry mouth, engaging a patient in a weight management program for antipsychoticassociated weight gain ${ }^{89}$ or prescribing another medication, eg, an anticholinergic drug to treat antipsychotic-induced Parkinsonism. Antipsychotic switching is another option to manage side effects, eg, switching from a prolactinelevating antipsychotic to a relatively prolactin-sparing antipsychotic to manage symptoms caused by prolactin elevation, such as galactorrhea or sexual dysfunction. ${ }^{90}$ Switching is most useful when there is clear evidence of the differences between antipsychotic drugs in their propensity to cause specific side effects. A recent meta-analysis helped to quantify the relative risk of various side effects, including hyperprolactinemia, extrapyramidal symptoms, and weight gain, for 15 antipsychotics. ${ }^{91}$ However, weaknesses in the evidence base mean that the relative risk of certain side effects is unclear for some antipsychotic drugs. ${ }^{92}$
Simplifying the treatment regimen can improve adherence in those with complex regimens. ${ }^{62}$ When nonadherence is due to forgetfulness, the use of a multicompartmental pillbox can be useful, although too few clinicians recognize that patients may not find these simple and that "training" may be needed. To aid adherence, communication between health professionals about a patient's condition needs to be clear, timely, and include information about current medications, including drug names, doses, and the reasons why each medication is prescribed. This is particularly important because patients with schizophrenia may receive care from multiple psychiatric teams within a short period (eg, inpatient team, community mental health team, crisis home treatment team) as well as the general practitioner.

\section{Psychosocial interventions Psychoeducation}

The term psychoeducation can be defined as an intervention that increases a patient's knowledge and understanding of a disorder. ${ }^{93}$ Psychoeducation has been offered in a variety of formats (individual, group, family), and courses range from one session to 25 or more sessions. It has been widely assumed that the knowledge gained through psychoeducation then enables someone with schizophrenia to cope more effectively with their illness. ${ }^{47,94}$ Although psychoeducation remains the most often recommended/utilized intervention in clinical practice, evidence is limited for its efficacy and effectiveness. ${ }^{93,95}$ The lack of potency of many generic psychoeducational interventions seems to reflect the fact that although patients' knowledge about medication improves with the provision of information, this alone does not translate into any change in adherence behavior. Furthermore, a review by Tacchi and $\operatorname{Scott}^{94}$ demonstrated that the psychoeducational models most likely to be beneficial incorporate "practical" learning exercises, behavioral reinforcement, and/or cognitive modifications, highlighting that information is a necessary but not sufficient component of such programs. Improved medication adherence has been reported to be one of several benefits of different models of family therapy or social skills training. ${ }^{96,97}$ However, apart from one trial, ${ }^{98}$ studies using family psychoeducation interventions to enhance adherence have shown mixed benefits.

\section{Behavioral interventions}

Behavioral interventions encompass skills building, practicing activities, behavioral modeling, and reinforcement strategies. A number of studies have shown behavioral interventions to be useful in improving medication adherence. ${ }^{99}$ 
Successful interventions tend to include psychoeducational elements as well as some individualization of treatment. For example, medication regimes adapted to the habits and routines of the patient, along with pairing daily medication intake with a specific regular behavior.

A study comparing treatment as usual with the MUSE (Medication Usage Skills for Effectiveness) program showed significant improvement in the intervention group. ${ }^{100}$ The MUSE program employed electronic pill bottles with caps displaying the date and time of each bottle opening and patients were taught to check the dose cap to see when their next dose of medication was due. This, along with other simple techniques of how to remember daily medication doses, helped improve adherence in patients with severe mental disorders.

A randomized study by Eckman et al compared a group behavioral program focusing on illness self-management with supportive group psychotherapy in outpatients with schizophrenia. ${ }^{101}$ The intervention comprised structured modules lasting about 3 hours per week over 4 months. The modules used video tapes, demonstrations, focused instruction, specialized role play, video feedback, and practice in the real world to focus on four skill areas, ie, information regarding the benefits of antipsychotic medication, correct self-administration, evaluation of medication effects and identifying side effects, and negotiating medication issues with health care professionals. Adherence significantly improved by $20 \%$ between the preintervention and postintervention assessments. However, it is notable that, as in many such studies, the baseline level of adherence in consenting participants was higher than often found in general psychiatry outpatients.

Tarrier et al examined medication adherence as one of several outcome measures in a study of patients with schizophrenia and their families. ${ }^{102}$ Brief behavioral interventions were compared with extended family therapy programs (about 9 months). The behavioral interventions focused on teaching the families skills "to manage schizophrenia", whilst the family therapy incorporated a broader range of approaches. Rates of medication adherence reached levels of approximately $70 \%$ for all patients, with no significant differences between groups.

\section{Motivational interviewing}

Motivational interviewing has been defined as a directive, client-centered counseling style that elicits behavioral change by helping clients to explore and resolve ambivalence. ${ }^{103}$ It includes behavioral analysis, and attempts to allow a person to discover the advantages and disadvantages of their behavior for themselves. It has been suggested that to be successful in improving medication adherence in schizophrenia, the intervention may require additional modifications to cope with the presence of negative symptoms. ${ }^{104}$

Compliance therapy utilizes motivational interviewing and cognitive behavioral approaches. The key techniques are those of reflective listening, regular summarizing, inductive questioning, exploring ambivalence, developing discrepancies between present behavior and broader goals, and using normalizing rationales. Kemp et al showed that 4-6 sessions of compliance therapy had a significantly greater effect upon adherence immediately post-intervention and at 18-month follow-up compared with 4-6 sessions of supportive counseling. ${ }^{105}$ However, two further studies of compliance therapy, ${ }^{106,107}$ including a large-scale pan-European trial in routine clinical settings, ${ }^{107}$ failed to find any specific benefit when compared with treatment as usual.

\section{Cognitive approaches}

Although cognitive approaches originally used adaptations of cognitive behavioral therapy to try to improve medication adherence, cognitive approaches now encompass neurocognitive remediation as well as traditional cognitive modification models. There is a large literature on the latter, suggesting that medication adherence improves in those who show other benefits from cognitive behavioral therapy, but that adherence alone probably does not explain all the clinical gains. ${ }^{94}$

Cognitive adaptation training (CAT) is a manual-driven intervention employing a series of compensatory strategies based on neuropsychological, behavioral, and occupational therapy principles. Training includes a comprehensive behavioral assessment to quantify the level of apathy and disinhibited behavior and neuropsychological assessment to examine the level of executive functioning, attention, and memory. Velligan et al randomly assigned 95 individuals with schizophrenia to either CAT focused on multiple aspects of community adaptation, CAT focused on medication adherence and appointment keeping, or to treatment as usual. ${ }^{108}$ Treatment lasted for 9 months and patients were followed up for 6 months after their home visits finished. The results showed that both CAT interventions improved medication adherence throughout the study period. The full CAT intervention improved functional outcome relative to the other two treatment groups, but this difference decreased after the home visits stopped. 


\section{Summary of psychosocial interventions}

The evidence from the studies reviewed shows that purely didactic psychoeducational interventions are the least effective for improving medication adherence. Successful forms of behavioral and cognitive interventions that improve medication adherence were those that: targeted and enhanced the therapeutic relationship; had a method for exploring the patient's model of their disorder, including their beliefs and expectations; and employed concrete problem-solving techniques. ${ }^{94}$ Although researchers often categorize the interventions according to a particular theoretical model, in reality it appears that interventions utilizing combined psychoeducation, cognitive and behavioral techniques, and homework strategies are more effective in increasing adherence than unidimensional approaches.

\section{Antipsychotic long-acting injections}

Antipsychotic LAIs were introduced in the 1960s to improve adherence. ${ }^{109}$ Several first-generation and second-generation antipsychotics are available as LAIs. Their main advantage is that they make covert nonadherence impossible. The comparative effectiveness of antipsychotic LAIs versus oral antipsychotics is sensitive to the research design. In three separate meta-analyses by study design, LAIs showed superiority to oral medication at endpoint in analyses of retrospective and prospective nonrandomized observational studies but showed no difference in relapse rates in a metaanalysis of RCTs. ${ }^{110}$ This difference is likely to reflect in part the recruitment of relatively adherent patients in RCTs and the research design altering the normal ecology of service delivery.

In the UK, five first-generation antipsychotic LAIs (flupentixol, fluphenazine, haloperidol, pipotiazine, zuclopenthixol) and four second-generation antipsychotic LAIs (risperidone, paliperidone, olanzapine, and aripiprazole) are currently available. A lack of head-to-head RCTs prevents direct comparisons between these agents. The side effect profiles of individual antipsychotic LAIs differ but are very similar to those of the corresponding drugs in oral form, although additional injection-related adverse effects can occur. ${ }^{111}$ Local adverse effects at the injection site are seen with all LAIs, and include pain, skin thickening, and nodules, but these problems are usually mild and/or infrequent. In addition, olanzapine pamoate can cause post-injection delirium/sedation syndrome (PDSS), the symptoms of which are consistent with an overdose of olanzapine and include sedation, confusion, slurred speech, disturbed gait, and unconsciousness. PDSS has not been observed with other antipsychotic LAIs. In a review of cases seen in clinical trials, PDSS occurred in approximately $0.07 \%$ of injections of olanzapine pamoate, with a median time of onset of 25 minutes post-injection, with all patients recovering within 72 hours. ${ }^{112}$ Individual LAIs differ with regard to licensed indication, cost (second-generation antipsychotic LAIs are far more expensive than first-generation antipsychotic LAIs), and a range of practical issues related to administration. The latter include approved injection site (deltoid and/or gluteal), needle gauge, injection interval, availability of prefilled syringes, requirement for oral antipsychotic supplementation when commencing the LAI or increasing the dose, and whether there is need for a post-injection observation period. ${ }^{113}$ The choice of which LAI to prescribe needs to be made on an individual patient basis and should take into account the differences between LAIs plus the individual's prior response to treatment with oral antipsychotics. The patient should be actively involved in the selection.

LAIs are one potential strategy to manage nonadherence, but are not suitable for all patients. Furthermore, a proportion of patients who start LAIs subsequently discontinue treatment. The attrition rate varies widely between studies; for example, one study found that over half of patients who started risperidone LAI had stopped it 6 months later, ${ }^{114}$ while another study reported a dropout rate of only $15 \%$ by 2 years. ${ }^{115}$ This variation may reflect many variables, including difference in patient characteristics, the dosing and initiation strategies adopted for the LAI, and the organization of services involved in prescribing, administering, and monitoring LAI treatment. LAIs are sometimes commenced as a treatment for detained inpatients (ie, those subject to compulsory treatment), but their use should still be based on a shared decision-making process, even if this acknowledges that at the time of initiation the clinician and patient have opposing views. In this situation, the aim is that, with time, the patient will gain insight into their illness and the role of medication, and ultimately agree to take medication when compulsory sanctions are removed. In the long-term, an LAI can only aid adherence if a patient agrees to take it.

There is comprehensive literature on the attitudes of health professionals and patients to LAIs. ${ }^{116}$ Most clinicians perceive that LAIs can be more effective than oral medication, but a minority perceive LAIs as old-fashioned, stigmatizing, and unsuitable for use in first-episode patients. ${ }^{117}$ Research on patients' views indicates that although some patients are strongly opposed to LAIs, others prefer an LAI to tablets. ${ }^{116}$ 
Furthermore, several studies show that LAIs are acceptable to at least a proportion of patients treated in early intervention services. ${ }^{118}$ Several researchers have argued that one barrier to the use of LAIs is the negative preconceptions that clinicians hold and in particular their belief that patients rarely want to consider an LAI. ${ }^{116}$ The attitudes of relatives to LAIs have been neglected, but one study indicated a more positive attitude than among patients. ${ }^{119}$

\section{Electronic reminders}

Reminders can be helpful when nonadherence is due to a patient forgetting to take medication or lacking a medicationtaking routine, ie, unintentional nonadherence. This approach is unlikely to help when nonadherence is the result of a deliberate decision by the patient. At its simplest, reminders may involve a patient having a written note to take medication that is placed in a prominent place, setting an alarm for when medication is due, or having medication prepacked in foils/blister packets labeled with the day and time that they are to be taken. Recently, there has been much interest in using mobile technology to provide patients with more sophisticated reminders and information about their medication-taking, and also to deliver other health interventions. Mobile phones are widely used in the general population, and Short Message Service (SMS) text messages provide a cheap, nonintrusive, and simple way to send information.

A systematic review of electronic reminders to improve patients' adherence with long-term medication in physical health disorders identified 13 controlled studies that used SMS reminders, audiovisual reminders, or pager messages. ${ }^{120}$ All three interventions, but especially SMS reminders, were effective, although most studies were short-term (follow-up period $<6$ months). In an RCT in clinically stable outpatients with schizophrenia, daily SMS reminders, sent over 3 months, improved patient-rated adherence with antipsychotic medication compared with a control group. ${ }^{121}$ The SMS group also showed a greater improvement in attitude toward medication and on several symptom ratings. The benefits in terms of adherence and attitudes reduced in the 3 months after the intervention ceased. A large randomized study (Mobile.net) of the effectiveness of SMS messages to improve adherence with antipsychotic medication is currently ongoing in Finland. ${ }^{122}$

A potential problem with routine SMS reminders is "message fatigue", ie, subjects receive reminders irrespective of whether or not they take their medication, and this may lead to the beneficial effect wearing off. This potential problem is overcome by real-time electronic medication monitoring, for which several systems are available. Most involve an electronic medication dispenser that registers when the dispenser is opened. This information is sent wirelessly in real time to a central server allowing a range of interventions. These include the server being programmed to send an SMS "reminder" text message to the patient if the dispenser is not opened within a specified time frame. This system has been reported to improve medication adherence in patients with type 2 diabetes. ${ }^{123}$

A real-time medication monitoring system was used in a recent trial in schizophrenia. Patients were randomized to a person-delivered or an electronic intervention to improve adherence or to treatment as usual. ${ }^{124}$ The electronic intervention was the Med-eMonitor, a "smart" pill container, the functions of which include reminding the patient to take medication by an alarm and wirelessly alerting staff if medication is not taken. This would lead a member of staff to telephone the patient and engage the individual in a discussion about adherence. The person-delivered intervention (a Cognitive Adaptation Training treatment [PharmCAT]) involved weekly home visits and an individualized approach to prompt medication-taking. Adherence was assessed electronically in all three groups using smart pill containers. Both interventions significantly improved adherence compared with treatment as usual, although clinical outcomes were unchanged. The electronic system was cheaper than the person-delivered intervention.

The electronic ingestible event marker or "smart tablet" (discussed in the previous section Assessment of nonadherence) has the potential to be used as a platform for a range of interventions to improve adherence. However, to date, no such intervention study has been reported, and the use of the system in schizophrenia has been limited to a small feasibility study. ${ }^{81}$

\section{Service interventions}

Ensuring that services are easily accessible to patients is likely to improve adherence. Examples include allocating appointments to patients with minimal delay and ensuring ready access to emergency services. The cost of antipsychotic medication can be a barrier to adherence. ${ }^{58}$ In some countries, annual prepayment cards can reduce the total cost of prescriptions over a year. Feedback to prescribers on whether patients collect prescriptions is not routinely used as an intervention to aid adherence. However, one US study reported a system in which prescribing clinicians and case managers were electronically messaged in real time if a patient prescription lapsed by 7 days, with further alerts following after longer lapse periods. ${ }^{79}$ They were also regu- 
larly sent MPR scores. The intervention was associated with improved MPR scores.

Many countries, including the USA, Canada, New Zealand, Australia, Israel, Sweden and England, have systems of compulsory psychiatric treatment for patients living in the community. The legal and clinical requirements vary, but in general they allow a clinician to stipulate a range of conditions for community treatment, including adherence with medication, and confer the power to readmit a patient to hospital if these conditions are broken, and this leads to significant clinical concern. The introduction of community treatment orders (CTOs) in England and Wales in 2008 was controversial, partly due to the ethical issues raised. ${ }^{125}$ Case-control studies have produced contradictory findings about the effectiveness of CTOs. ${ }^{126,127}$ Three RCTs of CTOs have been published, two from the USA conducted over a decade ago, ${ }^{128,129}$ and the Oxford Community Treatment Order Evaluation Trial from England, which was published in 2013. ${ }^{130}$ All three studies failed to show a difference in the primary outcome measure of readmission rates. In both Australia and England, CTOs are strongly associated with the use of antipsychotic LAIs. ${ }^{131}$ In a large mental health trust in England, nearly two thirds of those who were made subject to a CTO and had a diagnosis of schizophrenia were prescribed an LAI. ${ }^{132}$ This may perpetuate the "image problem" associated with LAIs, ie, it may promote the view that LAIs are a coercive treatment of last resort that is most suitable for difficult and challenging patients. In the UK, antipsychotic LAIs are prescribed for between a quarter and one third of patients with schizophrenia, ${ }^{133}$ the vast majority of whom are not legally compelled to take treatment.

\section{Financial incentives}

In many walks of life, it is well established that even small incentives or rewards can lead to behavior changes. Indeed, many more formal "behavioral" interventions, such as contingency management, were based on this idea. The use of incentives in rehabilitation services fell out of favor from about the 1960 s onwards because they were seen as inappropriate. ${ }^{134}$ Interestingly, as care has shifted increasingly to community settings, researchers have started to explore whether rewards or financial incentives may have a role to play.

Financial incentives to take medication are a behavioral intervention, although one that is controversial and raises ethical issues. ${ }^{135}$ The results of the first RCT of financial incentives to improve adherence with antipsychotic medication were recently published (Financial Incentives for Adherence Trial). ${ }^{136}$ Patients in the intervention group received $£ 15$ for each antipsychotic LAI they received, whereas patients in the control group received an LAI without any financial incentive. Over the 1-year trial period, adherence was significantly better in the intervention group than in the control group; the adjusted effect estimate was $11.5 \%$. The two groups did not differ in terms of clinician ratings of clinical improvement, but patient-rated quality of life was better in the intervention group. The authors concluded that modest financial incentives were effective in improving adherence with maintenance antipsychotics. This result is consistent with studies showing that financial incentives can modify health behavior in other areas of psychiatry and in general medicine. ${ }^{137-139}$

\section{Conclusion and future research}

Nonadherence with antipsychotic medication is a frequent problem in the management of schizophrenia. ${ }^{27,28}$ It leads to poorer patient outcomes, including an increased risk of relapse ${ }^{29,30}$ and reduced quality of life, ${ }^{33}$ as well as higher economic costs for inpatient care. ${ }^{41,42}$ Strategies to improve adherence have the potential to reduce these costs and as such adherence needs to be addressed more systematically in clinical practice. This is particularly relevant given the increasing pressure on resources in many health care systems. The causes of nonadherence are multiple and vary between patients. The use of relatively simple strategies by health care professionals can reduce the likelihood of nonadherence and facilitate its detection. These include good communication, shared decision-making about medication, and specific but nonjudgmental inquiry about adherence. It is often helpful to involve the family or the key carer in discussion about medication, assuming the patient agrees. There is no single solution to management of nonadherence, rather interventions must be targeted to the patient and tackle the contributory causes for that individual. Multidimensional approaches are more effective than unidimensional approaches. Improving adherence is an ongoing and dynamic process that requires the involvement of all health care professionals working with the patient.

Many areas in this field warrant further research. One is the impact of service design on adherence and other patient outcomes. In many countries, psychiatric services have become increasingly fragmented, with patients receiving care from multiple clinicians and teams at different stages of their illness. For example, in recent years, many services in England have separated consultant responsibility for inpatient and outpatient care; previously a single consultant would have provided care for the same patients whether they were inpatients or outpatients. This separation is controversial, ${ }^{140,141}$ in that it may improve quality of care and outcomes, but conversely, lack 
of consultant continuity may cause problems. For example, shared decision-making about medication may be undermined if a patient has brief interactions with many professionals, who may themselves hold differing views, rather than a close working alliance with selected individuals. Another area that has been relatively neglected is nonadherence with psychological treatments for schizophrenia. Cognitive behavioral therapy is an important treatment option in schizophrenia, although limited availability remains a problem in many services. In one observational study, $23 \%$ of those who started group cognitive behavioral therapy in a first-episode psychosis service did not complete treatment. ${ }^{142}$ A comparison of the factors linked to adherence with antipsychotic medication and cognitive behavioral therapy would be helpful to explore to what extent these are common and to help devise strategies to enhance engagement with psychological treatment.

Interventions to improve antipsychotic adherence would benefit from further research. These include the effect of financial incentives, given the positive result of the Financial Incentives for Adherence Trial, ${ }^{136}$ and what happens to adherence after financial incentives are stopped. The discrepancy between the results of observational studies and RCTs that have compared the effectiveness of antipsychotic LAIs and oral antipsychotics has been highlighted. ${ }^{110}$ This seems to partly result from an inherent bias, namely that RCTs selectively recruit relatively adherent patients. In addition, RCTs can alter the ecology of service delivery such that it is not representative of the use of LAIs and oral antipsychotics in the real world. We recommend that future RCTs use a comparative effectiveness strategy, and recruit and randomize patients to whom a clinician was considering recommending an LAI. Such studies should employ as few exclusion criteria as possible and have minimal research input after the baseline assessment and randomization, with the main outcome measure being the relapse rate or time to relapse. The use of smart pill boxes and real-time medication monitoring allows the linking of an objective measure of adherence with a behavioral intervention to enhance adherence. ${ }^{124}$ Wireless telemedicine can also be used to monitor a range of parameters, including early warning signs of relapse. ${ }^{143}$ Combining electronic monitoring of medication adherence and patient-reported clinical measures may help patients to assess better the pros and cons of medication and so improve adherence. The "smart pill" that records ingestion is a very recent development. ${ }^{81,82}$ Its acceptability, especially to severely ill patients, remains unclear and requires further study. With time, these electronic options may become less expensive and more widely available in routine practice rather than being confined to specialist or research settings. However, it is important always to bear in mind that none of these interventions can be a substitute for a carefully devised treatment plan that has been jointly agreed between the health care professional and the patient.

\section{Disclosure}

In the last 2 years, PMH has received fees for lecturing and/ or consultancy work (including attending advisory boards) from Bristol-Myers Squibb, Eli Lilly, Janssen, Lundbeck, Otsuka, Roche, Servier, Sunovion and Takeda. During the same period he has received support to attend conferences from Janssen, Otsuka, and Sunovion. In the past 2 years, CB has received honoraria for speaking and/or attending advisory boards from AstraZeneca, Eli Lilly, Roche, Janssen Pharmaceuticals, Takeda, Otsuka Pharmaceuticals, and Lundbeck. In the past 2 years, the NTW NHS Trust has received funding for research projects on medication adherence and training staff in the management of these problems from Astra Zeneca and Janssen Cilag. These unrestricted educational grants arose after successful grant applications designed and submitted by JS and colleagues. JS has also received honoraria for talks on psychosocial aspects of bipolar disorders from Astra Zeneca, Janssen Cilag, Eli Lilly, Sanofi Aventis, GSK, Lundbeck, and BMS Otsuka, and has attended advisory boards for Astra Zeneca, Janssen Cilag, Lundbeck, and BMS Otsuka.

\section{References}

1. Lerner BH. From careless consumptives to recalcitrant patients: the historical construction of noncompliance. Soc Sci Med. 1997;45: $1423-1431$.

2. Mohler DN, Wallin DG, Dreyfus EG. Studies in the home treatment of streptococcal disease. I. Failure of patients to take penicillin by mouth as prescribed. N Engl J Med. 1955;252:1116-1118.

3. National Institute for Health and Clinical Excellence. Medicines adherence involving patients in decisions about prescribed medicines and supporting adherence. January 2009. NICE clinical guideline 76. Available from: http://www.nice.org.uk/guidance/CG76. Accessed March 7, 2014.

4. World Health Organization. Adherence to long-term therapies: evidence for action. Geneva, Switzerland: World Health Organization; 2003. Available from: http://whqlibdoc. who.int/publications/2003/9241545992. pdf. Accessed March 7, 2014.

5. Karve S, Cleves MA, Helm M, Hudson TJ, West DS, Martin BC. Good and poor adherence: optimal cut-point for adherence measures using administrative claims data. Curr Med Res Opin. 2009;25:2303-2310.

6. Cramer JA, Rosenheck R. Compliance with medication regimens for mental and physical disorders. Psychiatr Serv. 1998;49:196-201.

7. Ram R, Bromet EJ, Eaton WW, Pato C, Schwartz JE. The natural course of schizophrenia: a review of first-admission studies. Schizophr Bull. 1992;18:185-207.

8. Robinson D, Woerner MG, Alvir JM, et al. Predictors of relapse following response from a first episode of schizophrenia or schizoaffective disorder. Arch Gen Psychiatry. 1999;56:241-247. 
9. Menezes NM, Arenovich T, Zipursky RB. A systematic review of longitudinal outcome studies of first-episode psychosis. Psychol Med. 2006;36:1349-1362.

10. Leucht S, Arbter D, Engel RR, Kissling W, Davis JM. How effective are second-generation antipsychotic drugs? A meta-analysis of placebocontrolled trials. Mol Psychiatry. 2009;14:429-447.

11. Leucht S, Tardy M, Komossa K, et al. Antipsychotic drugs versus placebo for relapse prevention in schizophrenia: a systematic review and meta-analysis. Lancet. 2012;379:2063-2071.

12. Mortimer AM, Singh P, Shepherd CJ, Puthiryackal J. Clozapine for treatment-resistant schizophrenia: National Institute of Clinical Excellence (NICE) guidance in the real world. Clin Schizophr Relat Psychoses. 2010;4:49-55.

13. Agid O, Arenovich T, Sajeev G, et al. An algorithm-based approach to first-episode schizophrenia: response rates over 3 prospective antipsychotic trials with a retrospective data analysis. J Clin Psychiatry. 2011;72:1439-1444.

14. Haddad PM, Sharma SG. Adverse effects of atypical antipsychotics: differential risk and clinical implications. CNS Drugs. 2007;21: 911-936.

15. Bushe CJ, Slooff CJ, Haddad PM, Karagianis JL. Weight change from 3-year observational data: findings from the worldwide schizophrenia outpatient health outcomes database. J Clin Psychiatry. 2012;73:749-755.

16. Newcomer JW. Metabolic syndrome and mental illness. Am J Manag Care. 2007;13(Suppl 7):S170-S177.

17. Graham SM, Howgate D, Anderson W, et al. Risk of osteoporosis and fracture incidence in patients on antipsychotic medication. Expert Opin Drug Saf. 2011;10:575-602.

18. Takeuchi H, Suzuki T, Remington G, et al. Effects of risperidone and olanzapine dose reduction on cognitive function in stable patients with schizophrenia: an open-label, randomized, controlled, pilot study. Schizophr Bull. 2013;39:993-998.

19. Morrison AP, Hutton P, Wardle M, et al. Cognitive therapy for people with a schizophrenia spectrum diagnosis not taking antipsychotic medication: an exploratory trial. Psychol Med. 2012;42: 1049-1056.

20. National Institute for Health and Care Excellence. Psychosis and schizophrenia in adults: treatment and management, National Clinical Guideline Number 178. Issued 2014. National Collaborating Centre for Mental Health Commissioned by the National Institute for Health and Care Excellence. Available from: http://www.nice.org.uk/nicemedia/ live/14382/66529/66529.pdf. Accessed April 4, 2014.

21. Davies MJ, Gagliardino JJ, Gray LJ, Khunti K, Mohan V, Hughes R. Real-world factors affecting adherence to insulin therapy in patients with type 1 or type 2 diabetes mellitus: a systematic review. Diabet Med. 2013;30:512-524.

22. Herttua K, Tabák AG, Martikainen P, Vahtera J, Kivimäki M. Adherence to antihypertensive therapy prior to the first presentation of stroke in hypertensive adults: population-based study. Eur Heart $J$ 2013;34:2933-2939.

23. Hermann MM, Bron AM, Creuzot-Garcher CP, Diestelhorst M. Measurement of adherence to brimonidine therapy for glaucoma using electronic monitoring. J Glaucoma. 2011;20:502-508.

24. Brook MG, Dale A, Tomlinson D, Waterworth C, Daniels D, Forster G. Adherence to highly active antiretroviral therapy in the real world: experience of twelve English HIV units. AIDS Patient Care STDS. 2001;15:491-494.

25. Lemstra M, Blackburn D, Crawley A, Fung R. Proportion and risk indicators of nonadherence to statin therapy: a meta-analysis. Can J Cardiol. 2012;28:574-580.

26. Byerly M, Fisher R, Whatley K, et al. A comparison of electronic monitoring vs clinician rating of antipsychotic adherence in outpatients with schizophrenia. Psychiatry Res. 2005;133:129-133.

27. Lacro JP, Dunn LB, Dolder CR, Leckband SG, Jeste DV. Prevalence of and risk factors for medication nonadherence in patients with schizophrenia: a comprehensive review of recent literature. J Clin Psychiatry. 2002;63:892-909.
28. Valenstein M, Ganoczy D, McCarthy JF, Myra Kim H, Lee TA, Blow FC. Antipsychotic adherence over time among patients receiving treatment for schizophrenia: a retrospective review. J Clin Psychiatry. 2006;67:1542-1550.

29. Ascher-Svanum H, Faries DE, Zhu B, Ernst FR, Swartz MS, Swanson JW. Medication adherence and long-term functional outcomes in the treatment of schizophrenia in usual care. J Clin Psychiatry. 2006;67(3):453-460.

30. Novick D, Haro JM, Suarez D, Perez V, Dittmann RW, Haddad PM. Predictors and clinical consequences of non-adherence with antipsychotic medication in the outpatient treatment of schizophrenia. Psychiatry Res. 2010;176:109-113.

31. Herings RM, Erkens JA. Increased suicide attempt rate among patients interrupting use of atypical antipsychotics. Pharmacoepidemiol Drug Saf. 2003;12:423-424.

32. Ward A, Ishak K, Proskorovsky I, Caro J. Compliance with refilling prescriptions for atypical antipsychotic agents and its association with the risks for hospitalization, suicide, and death in patients with schizophrenia in Quebec and Saskatchewan: a retrospective database study. Clin Ther. 2006;28:1912-1921.

33. Hayhurst KP, Drake RJ, Massie JA, et al. Improved quality of life over one year is associated with improved adherence in patients with schizophrenia. Eur Psychiatry. 2014;29:191-196.

34. Law MR, Soumerai SB, Ross-Degnan D, Adams AS. A longitudinal study of medication nonadherence and hospitalization risk in schizophrenia. J Clin Psychiatry. 2008;69:47-53.

35. Weiden PJ, Kozma C, Grogg A, Locklear J. Partial compliance and risk of rehospitalization among California Medicaid patients with schizophrenia. Psychiatr Serv. 2004;55:886-891.

36. Caseiro O, Pérez-Iglesias R, Mata I, et al. Predicting relapse after a first episode of non-affective psychosis: a three-year follow-up study. J Psychiatr Res. 2012;46:1099-1105.

37. Wiersma D, Nienhuis FJ, Sloof CJ, et al. Natural course of schizophrenic disorders: a 15-year follow-up of a Dutch incidence cohort. Schizophr Bull. 1998;24:75-85.

38. Lieberman JA, Koreen AR, Chakos M, et al. Factors influencing treatment response and outcome of first-episode schizophrenia: implications for understanding the pathophysiology of schizophrenia. $J$ Clin Psychiatry. 1996;57 Suppl 9:5-9.

39. van Haren NE, Hulshoff Pol HE, Schnack HG, et al. Focal gray matter changes in schizophrenia across the course of the illness: a 5-year follow-up study. Neuropsychopharmacology. 2007;32:2057-2066.

40. King D, Knapp M, Patel A, et al. The impact of non-adherence to medication in patients with schizophrenia on health, social care and societal costs. Analysis of the QUATRO study. Epidemiol Psychiatr Sci. 2013;10:1-10

41. Sun SX, Liu GG, Christensen DB, Fu AZ. Review and analysis of hospitalization costs associated with antipsychotic nonadherence in the treatment of schizophrenia in the United States. Curr Med Res Opin. 2007;23:2305-2312.

42. Dilla T, Ciudad A, Alvarez M. Systematic review of the economic aspects of nonadherence to antipsychotic medication in patients with schizophrenia. Patient Prefer Adherence. 2013;7:275-284.

43. Brain C, Allerby K, Sameby B, et al. Drug attitude and other predictors of medication adherence in schizophrenia: 12 months of electronic monitoring $\left(\mathrm{MEMS}^{\circledR}\right)$ in the Swedish COAST-study. Eur Neuropsychopharmacol. 2013;23:1754-1762.

44. Velligan DI, Lam F, Ereshefsky L, Miller AL. Psychopharmacology: perspectives on medication adherence and atypical antipsychotic medications. Psychiatr Serv. 2003;54:665-667.

45. Acosta F, Bosch E, Sarmiento G, Juanes N, Caballero-Hidalgo A, Mayans T. Evaluation of noncompliance in schizophrenia patients using electronic monitoring (MEMS) and its relationship to sociodemographic, clinical and psychopathological variables. Schizophr Res. 2009;107:213-217.

46. Loffler W, Kilian R, Toumi M, Angermeyer M. Schizophrenic patients' subjective reasons for compliance and noncompliance with neuroleptic treatment. Pharmacopsychiatry. 2003;36:105-112. 
47. Velligan D, Weiden P, Sajatovic M, et al. Expert consensus panel on adherence problems in serious and persistent mental illness. $J$ Clin Psychiatry. 2009;70 Suppl 4:1-46.

48. Lysaker PH, Vohs J, Hillis JD, et al. Poor insight into schizophrenia: contributing factors, consequences and emerging treatment approaches. Expert Rev Neurother. 2013;13:785-793.

49. Lepage M, Bodnar M, Joober R, Malla A. Is there an association between neurocognitive performance and medication adherence in first episode psychosis? Early Interv Psychiatry. 2010;4:189-195.

50. Chen EY, Hui CL, Dunn EL, et al. A prospective 3-year longitudinal study of cognitive predictors of relapse in first-episode schizophrenic patients. Schizophr Res. 2005;77:99-104.

51. Rettenbacher M, Hofer A, Eder U, et al. Compliance in schizophrenia: psychopathology, side effects, and patients' attitudes toward the illness and medication. J Clin Psychiatry. 2004;65:1211-1218.

52. Winklbaur B, Ebner N, Sachs G, Thau K, Fischer G. Substance abuse in patients with schizophrenia. Dialogues Clin Neurosci. 2006;8:37-43

53. Liu-Seifert H, Osuntokun OO, Feldman PD. Factors associated with adherence to treatment with olanzapine and other atypical antipsychotic medications in patients with schizophrenia. Compr Psychiatry. 2012;53:107-115

54. McCann TV, Clark E, Lu S. Subjective side effects of antipsychotics and medication adherence in people with schizophrenia. $J A d v$ Nurs. 2009;65:534-543.

55. Wong MM, Chen EY, Lui SS, Tso S. Medication adherence and subjective weight perception in patients with first-episode psychotic disorder. Clin Schizophr Relat Psychoses. 2011;5:135-141.

56. Lambert M, Conus P, Eide P, et al. Impact of present and past antipsychotic side effects on attitude toward typical antipsychotic treatment and adherence. Eur Psychiatry. 2004;19:415-422.

57. Fakhoury WK, Wright D, Wallace M. Prevalence and extent of distress of adverse effects of antipsychotics among callers to a United Kingdom National Mental Health Helpline. Int Clin Psychopharmacol. 2001;16:153-162.

58. Gibson TB, Jing Y, Kim E, et al. Cost-sharing effects on adherence and persistence for second-generation antipsychotics in commercially insured patients. Manag Care. 2010;19:40-47.

59. Kim E, Gupta S, Bolge S, Chen CC, Whitehead R, Bates JA. Adherence and outcomes associated with copayment burden in schizophrenia: a cross-sectional survey. J Med Econ. 2010;13:185-192.

60. de Vries ST, Keers JC, Visser R, et al. Medication beliefs, treatment complexity, and non-adherence to different drug classes in patients with type 2 diabetes. J Psychosom Res. 2014;76:134-138.

61. Rau JL. Determinants of patient adherence to an aerosol regimen. Respir Care. 2005;50:1346-1356.

62. Pfeiffer PN, Ganoczy D, Valenstein M. Dosing frequency and adherence to antipsychotic medications. Psychiatr Serv. 2008;59:1207-1210.

63. Beck EM, Cavelti M, Kvrgic S, Kleim B, Vauth R. Are we addressing the 'right stuff' to enhance adherence in schizophrenia? Understanding the role of insight and attitudes towards medication. Schizophrenia Res. 2011;132:42-49.

64. Hogan TP, Awad AG, Eastwood R. A self-report scale predictive of drug compliance in schizophrenics: reliability and discriminative validity. Psychol Med. 1983;13:177-183.

65. Yang J, Ko YH, Paik JW, et al. Symptom severity and attitudes toward medication: Impacts on adherence in outpatients with schizophrenia. Schizophr Res. 2012;134:226-231.

66. Fenton WS, Blyler CR, Heinssen RK. Determinants of medication compliance in schizophrenia: empirical and clinical findings. Schizophr Bull. 1997;23:637-651.

67. Ascher-Svanum H, Zhu B, Faries D, Lacro JP, Dolder CR. A prospective study of risk factors for nonadherence with antipsychotic medication in the treatment of schizophrenia. J Clin Psychiatry. 2006;67:1114-1123.

68. Sajatovic M, Jenkins JH. Is antipsychotic medication stigmatizing for people with mental illness? Int Rev Psychiatry. 2007;19:107-112.
69. Helbling J, Ajdacic-Gross V, Lauber C, Weyermann R, Burns T, Rössler W. Attitudes to antipsychotic drugs and their side effects: a comparison between general practitioners and the general population. BMC Psychiatry. 2006;6:42.

70. McCabe R, Bullenkamp J, Hansson L, et al. The therapeutic relationship and adherence to antipsychotic medication in schizophrenia. PLoS One. 2012;7:e36080.

71. Day JC, Bentall RP, Roberts C, et al. Attitudes toward antipsychotic medication: the impact of clinical variables and relationships with health professionals. Arch Gen Psychiatry. 2005;62:717-724.

72. McCabe R, Healey PG, Priebe S, et al. Shared understanding in psychiatrist-patient communication: association with treatment adherence in schizophrenia. Patient Educ Couns. 2013;93:73-79.

73. Zolnierek KB, Dimatteo MR. Physician communication and patient adherence to treatment: a meta-analysis. Med Care. 2009;47: 826-834.

74. McCann TV, Boardman G, Clark E, Lu S. Risk profiles for nonadherence to antipsychotic medications. J Psychiatr Ment Health Nurs. 2008;15:622-629.

75. Brain C, Sameby B, Allerby K, et al. Twelve months of electronic monitoring $\left(\mathrm{MEMS}^{\circledR}\right)$ in the Swedish COAST-study: a comparison of methods for the measurement of adherence in schizophrenia. Eur Neuropsychopharmacol. 2014;24:215-222.

76. Velligan DI, Lam YWF, Glahn DC, et al. Defining and assessing adherence to oral antipsychotics: a review of the literature. Schizophr Bull. 2006;32:724-742

77. Nakonezny PA, Byerly MJ, Rush AJ. Electronic monitoring of antipsychotic medication adherence in outpatients with schizophrenia or schizoaffective disorder: an empirical evaluation of its reliability and predictive validity. Psychiatry Res. 2008;157:259-263.

78. Goff DC, Hill M, Freudenreich O. Strategies for improving treatment adherence in schizophrenia and schizoaffective disorder. $J$ Clin Psychiatry. 2010;71 Suppl 2:20-26.

79. Patel UB, Ni Q, Clayton C, Lam P, Parks J. An attempt to improve antipsychotic medication adherence by feedback of medication possession ratio scores to prescribers. Popul Health Manag. 2010;13:269-274.

80. Velligan DI, Wang M, Diamond P, et al. Relationships among subjective and objective measures of adherence to oral antipsychotic medications. Psychiatr Serv. 2007;58:1187-1192.

81. Kane JM, Perlis RH, DiCarlo LA, Au-Yeung K, Duong J, Petrides G. First experience with a wireless system incorporating physiologic assessments and direct confirmation of digital tablet ingestions in ambulatory patients with schizophrenia or bipolar disorder. $J$ Clin Psychiatry. 2013;74:e533-e540.

82. Au-Yeung KY, Moon GD, Robertson TL, et al. Early clinical experience with networked system for promoting patient self-management. Am J Manag Care. 2011;17:e277-e287.

83. Read J. Coping with Coming Off: Minds Research into the Experience of People Trying to Come Off Psychiatric Drugs. London, UK: Mind Publications; 2005.

84. Williams GC, Rodin GC, Ryan RM, Grolnick WS, Deci EL. Autonomous regulation and long-term medication adherence in adult outpatients. Health Psychol. 1998;17:269-276.

85. Wilder CM, Elbogen EB, Moser LL, Swanson JW, Swartz MS. Medication preferences and adherence among individuals with severe mental illness and psychiatric advance directives. Psychiatr Serv. 2010;61:380-385.

86. McCabe R, Khanom H, Bailey P, Priebe S. Shared decision-making in ongoing outpatient psychiatric treatment. Patient Educ Couns. 2013;91:326-328

87. Haddad PM, Fleischhacker WW, Peuskens P, et al. SMARTS (Systematic Monitoring of Adverse events Related to TreatmentS): the development of a pragmatic patient completed checklist to assess antipsychotic drug side effects. Ther Adv Psychopharmacol. 2014;4:15-21.

88. Waddell L, Taylor M. A new self-rating scale for detecting atypical or second-generation antipsychotic side effects. J Psychopharmacol. 2008;22:238-243. 
89. Pendlebury J, Haddad P, Dursun S. Evaluation of a behavioural weight management programme for patients with severe mental illness: 3 year results. Hum Psychopharmacol. 2005;20:447-448.

90. Haddad PM, Hellewell JS, Wieck A. Antipsychotic induced hyperprolactinaemia: a series of illustrative case reports. J Psychopharmacol. 2001;15:293-295.

91. Leucht S, Cipriani A, Spineli L, et al. Comparative efficacy and tolerability of 15 antipsychotic drugs in schizophrenia: a multipletreatments meta-analysis. Lancet. 2013;382:951-962.

92. Hamer S, Haddad PM. Adverse effects of antipsychotics as outcome measures. Br J Psychiatry Suppl. 2007;50:s64-s70.

93. Pekkala E, Merinder L. Psychoeducation for schizophrenia. Cochrane Database Syst Rev. 2002;2:CD002831.

94. Tacchi MJ, Scott J. Improving Adherence in Schizophrenia and Bipolar Disorders. Chichester, UK: J Wiley \& Sons Ltd; 2005.

95. Dolder CR, Lacro JP, Leckband S, Jeste DV. Interventions to improve antipsychotic medication adherence: review of recent literature. J Clin Psychopharmacol. 2003;23:389-399.

96. Falloon IR, Boyd JL, McGill CW, et al. Family management in the prevention of morbidity of schizophrenia. Clinical outcome of a twoyear longitudinal study. Arch Gen Psychiatry. 1985;42:887-896.

97. Hogarty GE, Anderson CM, Reiss DJ, et al. Family psychoeducation, social skills training, and maintenance chemotherapy in the aftercare treatment of schizophrenia. II. Two-year effects of a controlled study on relapse and adjustment. Arch Gen Psychiatry. 1991;48: 340-347.

98. Xiong W, Phillips MR, Hu X, et al. Family-based intervention for schizophrenic patients in China. A randomised controlled trial. $\mathrm{Br} J$ Psychiatry. 1994;165:239-247.

99. Boczkowski JA, Zeichner A, DeSanto N. Neuroleptic compliance among chronic schizophrenic outpatients: an intervention outcome report. J Consult Clin Psychol. 1985;53:666-671.

100. Cramer JA, Rosenheck R. Enhancing medication compliance for people with serious mental illness. J Nerv Ment Dis. 1999;187:53-55.

101. Eckman TA, Wirshing WC, Marder SR, et al. Technique for training schizophrenic patients in illness self-management: a controlled trial. Am J Psychiatry. 1992;149:1549-1555.

102. Tarrier N, Barrowclough C, Vaughn C, et al. The community management of schizophrenia. A controlled trial of a behavioural intervention with families to reduce relapse. Br J Psychiatry. 1988;153: 532-542.

103. Rollnick S, Miller WR. What is motivational interviewing? Behav Cogn Psychother. 1995;23:325-335.

104. Rüsch N, Corrigan PW. Motivational interviewing to improve insight and treatment adherence in schizophrenia. Psychiatr Rehabil J. 2002;26:23-32.

105. Kemp R, Kirov G, Everitt B, Hayward P, David A. Randomised controlled trial of compliance therapy: 18-month follow-up. $\mathrm{Br} J$ Psychiatry. 1998;172:413-419.

106. O’Donnell C, Donohoe G, Sharkey L, et al. Compliance therapy: a randomised controlled trial in schizophrenia. BMJ. 2003;327:834.

107. Gray R, Leese M, Bindman J, et al. Adherence therapy for people with schizophrenia. European multicentre randomised controlled trial. Br J Psychiatry. 2006;189:508-514.

108. Velligan DI, Diamond PM, Maples NJ, et al. Comparing the efficacy of interventions that use environmental supports to improve outcomes in patients with schizophrenia. Schizophr Res. 2008;102:312-319.

109. Johnson DA. Historical perspective on antipsychotic long-acting injections. Br J Psychiatry Suppl. 2009;52:S7-S12.

110. Kirson NY, Weiden PJ, Yermakov S, et al. Efficacy and effectiveness of depot versus oral antipsychotics in schizophrenia: synthesizing results across different research designs. J Clin Psychiatry. 2013;74: 568-575.

111. Haddad P, Fleischhacker WW. Adverse effects and antipsychotic long-acting injections. In: Peter Haddad, Tim Lambert, John Lauriello, editors. Antipsychotic Long-Acting Injections. Oxford, UK: Oxford University Press; 2011.
112. Detke HC, McDonnell DP, Brunner E, et al. Post-injection delirium/ sedation syndrome in patients with schizophrenia treated with olanzapine long-acting injection. I: analysis of cases. BMC Psychiatry. 2010;14:43.

113. Citrome L. New second-generation long-acting injectable antipsychotics for the treatment of schizophrenia. Expert Rev Neurother. 2013;13:767-783.

114. Taylor DM, Young CL, Mace S, Patel MX. Early clinical experience with risperidone long-acting injection: a prospective, 6-month follow-up of 100 patients. J Clin Psychiatry. 2004;65:1076-1083.

115. Peuskens J, Olivares JM, Pecenak J, et al. Treatment retention with risperidone long-acting injection: 24-month results from the Electronic Schizophrenia Treatment Adherence Registry (e-STAR) in six countries. Curr Med Res Opin. 2010;26:501-509.

116. Waddell L, Taylor M. Attitudes of patients and mental health staff to antipsychotic long-acting injections: systematic review. BrJ Psychiatry Suppl. 2009;52:S43-S50.

117. Patel MX, Haddad PM, Chaudhry IB, McLoughlin S, Husain N, David AS. Psychiatrists' use, knowledge and attitudes to first- and second-generation antipsychotic long-acting injections: comparisons over 5 years. J Psychopharmacol. 2010;24:1473-1482.

118. Emsley R, Chiliza B, Asmal L, Mashile M, Fusar-Poli P. Long-acting injectable antipsychotics in early psychosis: a literature review. Early Interv Psychiatry. 2013;7:247-254.

119. Jaeger M, Rossler W. Attitudes towards long-acting depot antipsychotics: a survey of patients, relatives and psychiatrists. Psychiatry Res. 2010;175:58-62.

120. Vervloet M, Linn AJ, van Weert JC, de Bakker DH, Bouvy ML, van Dijk L. The effectiveness of interventions using electronic reminders to improve adherence to chronic medication: a systematic review of the literature. J Am Med Inform Assoc. 2012;19:696-704.

121. Montes JM, Medina E, Gomez-Beneyto M, Maurino J. A short message service (SMS)-based strategy for enhancing adherence to antipsychotic medication in schizophrenia. Psychiatry Res. 2012;200:89-95.

122. Välimäki M, Hätönen H, Adams CE. Mobile.net: Mobile Telephone Text messages to encourage adherence to medication and to follow up with people with psychosis: methods and protocol for a multicenter randomized controlled two-armed trial. JMIR Res Protoc. 2012;1:e8.

123. Vervloet M, van Dijk L, Santen-Reestman J, et al. SMS reminders improve adherence to oral medication in type 2 diabetes patients who are real time electronically monitored. Int J Med Inform. 2012;81: 594-604.

124. Velligan D, Mintz J, Maples N, et al. A randomized trial comparing in person and electronic interventions for improving adherence to oral medications in schizophrenia. Schizophr Bull. 2013;39:999-1007.

125. Burns T, Dawson J. Community treatment orders: how ethical without experimental evidence? Psychol Med. 2009;39:1583-1586.

126. Maughan D, Molodynski A, Rugkåsa J, Burns T. A systematic review of the effect of community treatment orders on service use. Soc Psychiatry Psychiatr Epidemiol. October 18, 2013. [Epub ahead of print.]

127. Churchill R, Owen G, Singh S, Hotopf M. International Experiences of Using Community Treatment Orders. London, UK: Institute of Psychiatry; 2007. Available from: http://psychrights.org/research/Digest/ OutPtCmmtmnt/UKRptonCTO.pdf. Accessed March 8, 2014.

128. Steadman HJ, Gounis K, Dennis D, et al. Assessing the New York City involuntary outpatient commitment pilot program. Psychiatr Serv. 2001;52:330-336.

129. Swartz MS, Swanson JW, Wagner HR, Burns BJ, Hiday VA, Borum R. Can involuntary outpatient commitment reduce hospital recidivism? Findings from a randomized trial with severely mentally ill individuals. Am J Psychiatry. 1999;156:1968-1975.

130. Burns T, Rugkåsa J, Molodynski A, et al. Community treatment orders for patients with psychosis (OCTET): a randomised controlled trial. Lancet. 2013;381:1627-1633.

131. Lambert TJ, Singh BS, Patel M. Community treatment orders and antipsychotic long-acting injections. Br J Psychiatry. 2009;95 Suppl 52: s57-s62. 
132. Patel MX, Matonhodze J, Baig MK, et al. Increased use of antipsychotic long-acting injections with community treatment orders. Ther Adv Psychopharmacol. 2011;1:37-45.

133. Barnes TR, Shingleton-Smith A, Paton C. Antipsychotic long-acting injections: prescribing practice in the UK. Br J Psychiatry Suppl. 2009;52:S37-S42.

134. Dickerson FB, Tenhula WN, Green-Paden LD. The token economy for schizophrenia: review of the literature and recommendations for future research. Schizophr Res. 2005;75:405-416.

135. Giuffrida A, Torgerson DJ. Should we pay the patient? Review of financial incentives to enhance patient compliance. BMJ. 1997;315: 703-707.

136. Priebe S, Yeeles K, Bremner S, et al. Effectiveness of financial incentives to improve adherence to maintenance treatment with antipsychotics: cluster randomised controlled trial. BMJ. 2013;347:f5847.

137. Schierenberg A, van Amsterdam J, van den Brink W, Goudriaan AE. Efficacy of contingency management for cocaine dependence treatment: a review of the evidence. Curr Drug Abuse Rev. 2012;5: $320-331$

138. Burton A, Marougka S, Priebe S. [Do financial incentives increase treatment adherence in people with severe mental illness? A systematic review]. Epidemiol Psichiatr Soc. 2010;19:233-242. Italian.
139. Giuffrida A, Torgerson DJ. Should we pay the patient? Review of financial incentives to enhance patient compliance. BMJ. 1997;315: 703-707.

140. Burns T. The dog that failed to bark. Psychiatrist. 2010;34:361-363.

141. Laugharne R, Pant M. Sector and functional models of consultant care: in-patient satisfaction with psychiatrists. Psychiatrist. 2012;36:254-256.

142. Fanning F, Foley S, Lawlor E, et al. Group cognitive behavioural therapy for first episode psychosis: who's referred, who attends and who completes it? Early Interv Psychiatry. 2012;6:432-441.

143. Spaniel F, Vohlídka P, Hrdlicka J, et al. ITAREPS: information technology aided relapse prevention programme in schizophrenia. Schizophr Res. 2008;98:312-317.

144. DerSimonian R, Laird N. Meta-analysis in clinical trials. Contr Clin Trials. 1986;7:177-188.

145. Altman DG. Confidence intervals for the number needed to treat. $B M J$ 1998;317:1309-1312.

146. Haddad P, Lambert T, Lauriello J. The role of antipsychotic long-acting injections in current practice. In: Peter Haddad, Tim Lambert, John Lauriello, editors. Antipsychotic Long-Acting Injections. Oxford, UK: Oxford University Press; 2011.
Patient Related Outcome Measures

\section{Publish your work in this journal}

Patient Related Outcome Measures is an international, peer-reviewed, open access journal focusing on treatment outcomes specifically relevant to patients. All aspects of patient care are addressed within the journal and practitioners from all disciplines are invited to submit their work as well as healthcare researchers and patient support groups.

\section{Dovepress}

The manuscript management system is completely online and includes a very quick and fair peer-review system. Visit http://www.dovepress. com/testimonials.php to read real quotes from published authors. 